\title{
THE EFFECTS OF TEXT COMPLEXITY AND COMPLEX GRAPHICAL ELEMENTS ON READERS' TEXT COMPREHENSION OF ONLINE SCIENCE ARTICLES
}

\author{
A Thesis presented to \\ the Faculty of the Graduate School \\ at the University of Missouri-Columbia
}

In Partial Fulfillment

of the Requirements for the Degree

Masters of Arts

by

ANNE SALAZAR

Dr. Paul Bolls, Thesis Supervisor

MAY 2009 
The undersigned, appointed by the dean of the Graduate School, have examined the thesis entitled

\section{THE EFFECTS OF TEXT COMPLEXITY AND COMPLEX GRAPHICAL ELEMENTS ON READERS' TEXT COMPREHENSION OF ONLINE SCIENCE ARTICLES}

presented by Anne Salazar, a candidate for the degree of master of arts, and hereby certify that, in their opinion, it is worthy of acceptance.

Professor Paul Bolls

Professor Bill Allen

Professor Kevin Wise

Professor Antonie Stam 


\section{DEDICATIONS}

I would like to thank my Mom, Dad, and brother for supporting me over these last few years, and send a big thank you to my parents for giving me the opportunity to get a good education.

I would also like to thank all of my friends I have made here at Mizzou. Thank you for standing by me these few years and putting up with my unusual and sometimes hectic work schedule as I strived to accomplish my goals. 


\section{ACKNOWLEDGEMENTS}

Thank you to my committee members for all of your guidance and support.

Thesis advisor: Paul Bolls, Strategic Communication

Committee members: Antonie Stam, Management

Bill Allen, Agricultural Journalism

Kevin Wise, Strategic Communication

Thank you to Paul Bolls for standing by me through the ups and downs, even though there seemed to be more downs than ups, and a huge thank you to all those of the PRIME lab for allowing me to use it for my work and being amazing sources for insight and advice. 


\section{TABLE OF CONTENTS}

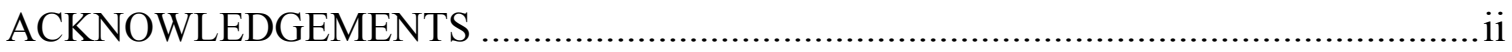

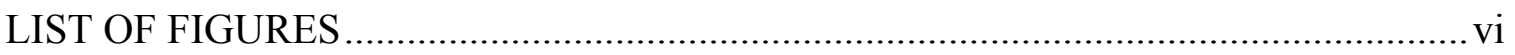

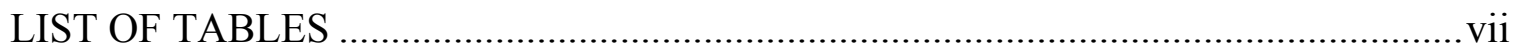

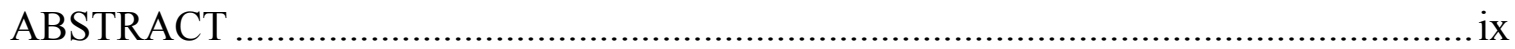

Chapter

INTRODUCTION

Goals of the Study

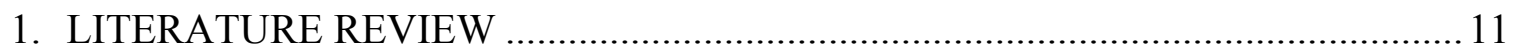

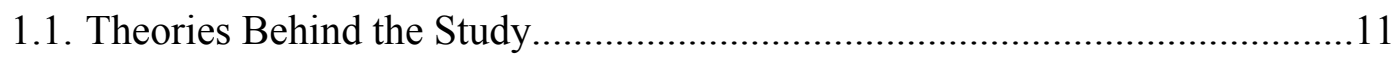

1.1.1. Construction and Integration Model (C-I).......................................13

1.1.2. Limited Capacity Model of Motivated Mediated Message Processing .................................................................................16

1.2. Understanding Science and Technology Literacy...........................................19

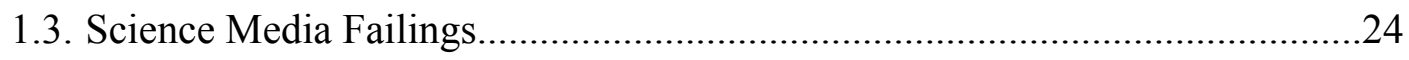

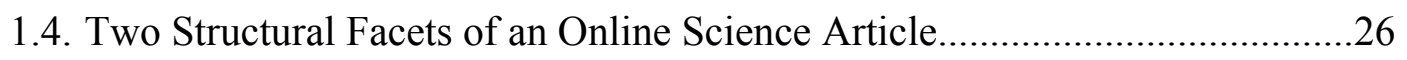

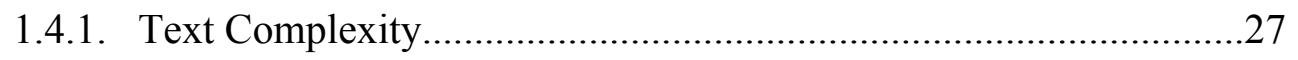

1.4.2. Complex Graphical Elements..........................................................30

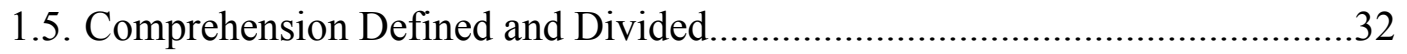

1.5.1. Recognition Memory .............................................................................

1.5.2. Problem-solving Recall Memory......................................................41

1.5.3. The perception of an online science article........................................42

1.6. The Influence of the Structural Facets of an Online Science Article On a Reader's Text Comprehension........................................................................43

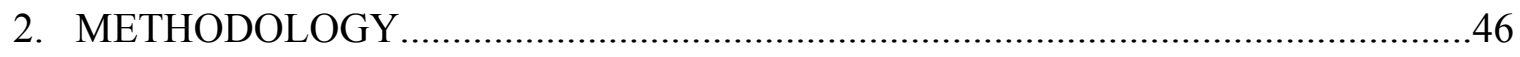

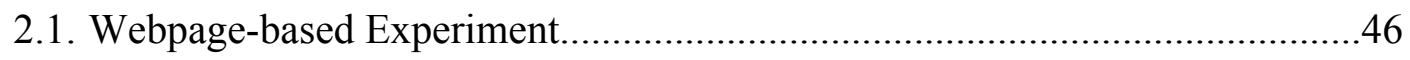




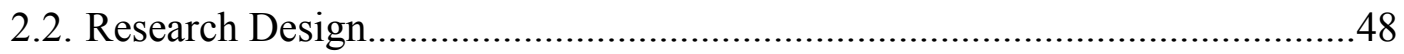

2.3. Participants and Research Procedures...............................................................54

2.4. Independent Variables..................................................................................5

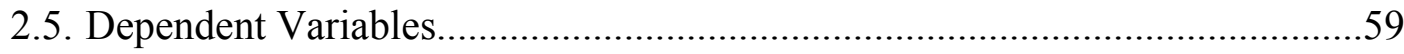

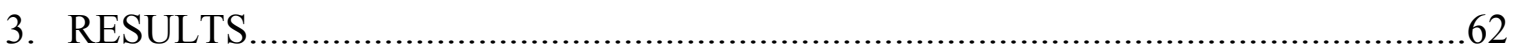

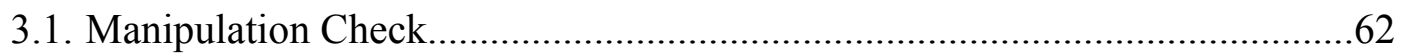

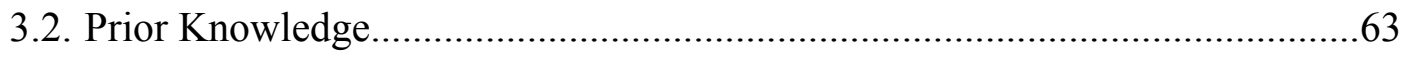

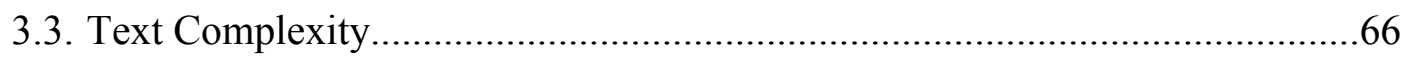

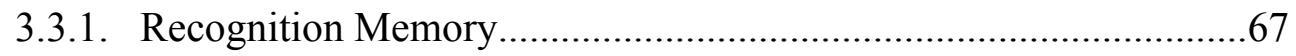

3.3.2. Problem-solving Recall Memory.......................................................69

3.4. The Presence of Complex Graphical Elements..................................................71

3.4.1. Recognition Memory ......................................................................... 71

3.4.2. Problem-solving Recall Memory ........................................................73

3.4.3. Text Complexity and Complex Graphical Elements..........................74

3.5. The Perception of an Online Science Article..................................................76

3.5.1. Does Perception Correlate With Prior Knowledge?...........................76

3.5.2. Does Perception Correlate With Actual Text Comprehension?........77

4. DISCUSSION AND CONCLUSIONS...................................................................79

4.1. Summary of the Results..............................................................................79

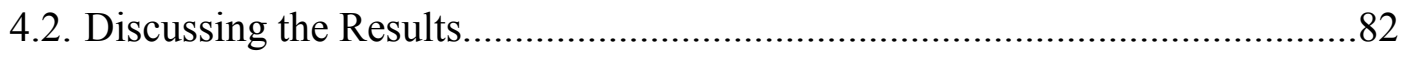

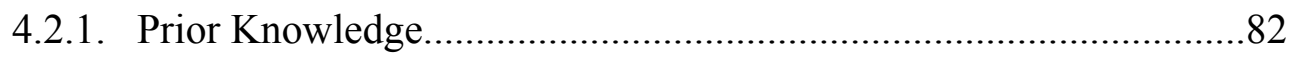

4.2.2. Text Complexity...............................................................................

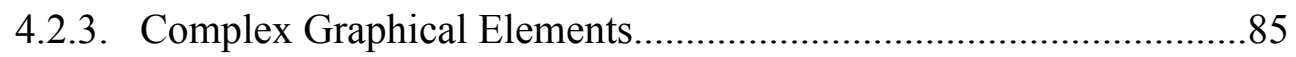

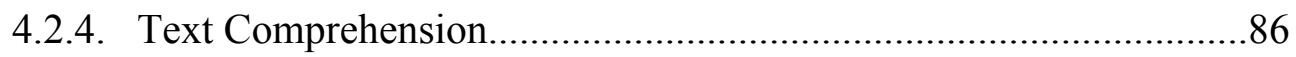

4.3. Limitations of the Research and Future Research..........................................90 
4.4. What it Means to Current Research..............................................................94

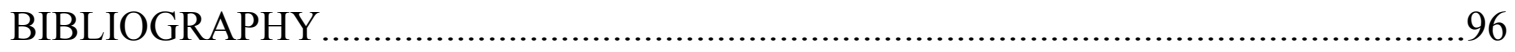




\section{LIST OF FIGURES}

$\begin{array}{lll}\text { Figure } & \text { Page }\end{array}$

1. The C-I network of propositions used in the sequence............................................ 14

2. The structural facets cross in a $2 \mathrm{X} 2$ for this study................................................. 27

3. This thesis' research questions modelled out as a chart. ...........................................36

4. The research questions' model with the three parts of text comprehension..............39

5. This graph illustrates the recognition memory questions mean scores in terms of how each level of text complexity influences it, and how that influence varies with

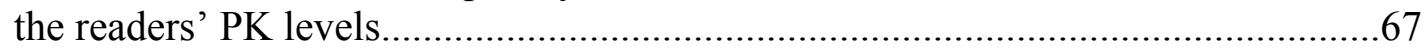

6. This graph illustrates the problem-solving recall memory questions means scores in terms of how each level of text complexity influences it, and how that influence varies with the readers' PK levels...........................................................................

7. The graph illustrates the text complexity mean scores for Question 11 in terms of how each level of CGE influences the results. 


\section{LIST OF TABLES}

Table

1. Example paragraphs varied according to the two levels of text complexity.

2. The articles examined in terms of the two levels of the two structural facets.........50

3. The text complexity levels according to the Flesch-Kincaid Readability Test .......58

4. The means scores for Question 9 found by a repeated measures ANOVA for assumed text complexity correlating to perceived text complexity.....

5. The mean scores found for Question 9 in terms of the CGE levels and the text complexity levels, ignoring readers' PK levels.

6. These are the frequencies of the participants' scores used in the final analysis of this study's results

7. These frequencies refer to the current level of education identified by the participants, and they are broken up according to readers' PK levels.

8. These frequencies refer to the participants' programs of study, which they specified from a list, and they are broken up according to the two PK levels.

9. These frequencies refer to how many times per month the participants specified they read science magazines, and they are broken up according to the two PK levels.....66

10. The mean scores found by a paired-samples T-test for the influence of the two PK levels and the two text complexity levels on recognition memory questions. .68

11. The mean scores found by a repeated measures ANOVA for the interaction between the two text complexity levels and the two PK levels for the problem-solving memory questions

12. The mean scores found by a paired-samples T-test for the influence of the two PK levels and the two text complexity levels on problem-solving recall memory questions.

13. The mean scores found by a repeated measures ANOVA for the interaction between the two CGE levels and the two PK levels for the recognition memory questions.

14. The means found by a paired-samples T-test for the influence of the two CGE levels and the two PK levels on recognition memory questions. 
15. The mean scores found by a repeated measures ANOVA for the interaction between the two CGE levels and the two PK levels for the problem-solving recall memory questions.

16. The mean scores found by a paired-samples T-test for the influence of the two CGE levels and the two PK levels on problem-solving recall memory questions.

17. The mean scores found by a repeated measures ANOVA for the interaction between the two text complexity levels and the two CGE levels.

18. The mean scores found by a repeated measures ANOVA for the interaction between the two text complexity levels, the two CGE levels, and the two PK levels..............75

19. The mean scores found for Question 11 in terms of the two text complexity levels and the two CGE levels, ignoring readers' PK levels.

20. The bivariate correlation results concerning Question 12 of the post-reading questionnaire. 


\begin{abstract}
Science literacy (SL) allows an individual to be knowledgeable on the latest science research and to draw "evidence-based conclusions." Unfortunately, only a small portion of the U.S. public is scientifically literate. Thus, this study investigated how a science communicator could increase SL. The researcher performed a Webpage-based experiment about how two structural facets of a science article influence a reader's text comprehension. After examining text complexity and the presence of complex graphic elements $(\mathrm{CGE})^{\mathrm{ii}}$, text complexity by itself showed significant influence. Hence, text complexity does influence readers' text comprehension, particularly for low prior knowledge $(\mathrm{PK})^{\mathrm{i}}$ readers. When these readers have difficulty reading the text, they use more cognitive resources for the interpretation of it instead of retrieving information. The low PK readers then are less likely to comprehend the message of the science article.

The presence of CGE interacted with text complexity for the article's perceived ability to explain the topic. Participants understood the topic best when it was low text complexity and no CGE were present. For actual text comprehension, the results were not significant but suggested that low PK readers found CGE influential with high text complexity science articles for problem-solving questions and all text complexities for recognition questions. Therefore, low PK readers reading science articles need either more casual and referential connections in the text or CGE with it. The study found no definite results for high PK readers, but CGE's presence or absence had no substantial effect and the two levels of text complexities showed only the smallest of variation in their results.
\end{abstract}




\section{INTRODUCTION}

The purpose of this study was to examine a reader's text comprehension of an online science article and see how its structural facets might influence the reader's ability to comprehend the science or technology topic. Earlier studies have shown that there are numerous factors influencing comprehension when reading texts. These factors included reader characteristics, text properties, page properties, and text presentation. All factors can influence reading in terms of both remembering and learning. Many of these can be controlled or manipulated, and all are measurable either alone or in conjunction with other factors. This study examined a text property, a page property, and a reader characteristic. The first two factors were facets of the text's structure, and so the researcher calls them structural facets. The researcher expected to gain a more clear understanding of how these structural facets trigger and hinder text comprehension. There was an expectation from earlier studies that the influence varies according to the reader characteristic of prior knowledge (PK) ${ }^{\mathrm{i}}$ (Caillies, Denhière, \& Kintsch, 2002; McNamara, Kintsch, Singer, \& Kintsch, 1996; Kendeou \& van den Broek, 2007; Sanjosé, VidalAbarca, \& Padilla, 2006; Salmerón, Kintsch, \& Cañas, 2006; Brooks, Arnold, \& Iacobbo, 1977).

The goal of this study was to gain an understanding of how these structural facets vary in impact, so that the science media and writers can improve how they communicate scientific topics and write for a wider audience (Kua, Reder, \& Grossel, 2004; Long, 1995). In turn, the researcher hoped that a greater percentage of the general population would be able to more easily and efficiently read science articles, and as a result, become 
better informed about the areas of science and technology (Miller, 1998, 2004; Pardo \& Calvo, 2004; Field \& Powell, 2001). A society whose people are more knowledgeable can, hopefully, perform more proficiently and make wiser decisions that affect itself, those around it, and the world it exists in (Miller, 1998, 2004; Pardo \& Calvo, 2004).

For this study, the two structural facets examined were text complexity and visuals, specifically complex graphical elements $(\mathrm{CGE})^{\mathrm{ii}}$. Text complexity and visuals, in previous studies, had some influence on text comprehension in the areas of education, newspapers, and psychology. In fact, charts and graphs require a reader to have a good ability to read and understand the text within them (Friel, Curcio, \& Bright, 2001; Newton, 1994; Curcio, 1987). Therefore, this study hoped to see the following:

1. Do similar results exist for the science media?

2. Do the influences vary between different PK levels?

3. Is there an interaction between the two chosen structural facets of the science article? (Hanley, Herron, \& Cole, 1995; Friel et al., 2001; Newton, 1994; Curcio, 1987; Herron, Cole, Corrie, \& Dubreil, 1999; Adaval, Isbell, \& Wyer, 2005).

Text complexity or coherence is a structural facet that exists in every type of science coverage. It can involve both the structure and the content of the text. In previous research, the definition of text complexity has included the use of topic terminology, the use of casual and referential connections, and the organization of the text in a way that the reader easily understands, i.e. logical layout or flow from point to point. All three methods for defining text complexity relate to the others, but they tend to focus on the word level of the text, the sentence level of the text, or the paragraph level of the text. 
For example, working with casual and referential connections places examination and manipulation on either the sentence or the paragraph level. In other words, any distinction between texts of different text complexity levels will be more visible when a reader examines an entire sentence or paragraph. The complexity or coherence will be due to the difference in descriptions, definitions, and phrasing. Casual and referential connections occur during an inferential process, which takes place when there is an interruption in the forming of mental representations. When a reader loses the ability to coherently read and take in the knowledge, he or she must then use his or her own knowledge to fill in the gaps of missing information (Table 1). Thus, with more casual and referential connections, a reader does not need to infer as much. Instead, the reader focuses on integrating new ideas from the text with his or her current level of PK. This is a process known as assimilation (Macedo-Rouet, Rouet, Epstein, and Fayard, 2003; Caillies et al., 2002; Lin, Zabrucky, \& Moore, 2002; Yarros, 2006; McNamara, Kintsch, Singer, \& Kintsch, 1996; Kendeou \& van den Broek, 2007; McKeown, Beck, Sinatra, \& Loxterman, 1992; Linderholm, Everson et al., 2000). The table below shows an article dealing with the genetic manipulation of crops to increase production. The two variations contrast according to the inclusion or absence of the basic plant physiology explanations about photosynthesis, or focus more on the current findings than their connection to previous scientific theory (Mann, 1999). 


\begin{tabular}{|l|l}
\hline Low Text Complexity & $\begin{array}{l}\text { RuBisCO is the most abundant protein and important enzyme known by } \\
\text { science today. It is the trigger for a plant's central process of creating and } \\
\text { storing energy, called photosynthesis, and creates carbon needed by all } \\
\text { living creatures. By interacting with carbon found in the atmosphere, it } \\
\text { creates the carbohydrates, the proteins, and the fats for all living plants } \\
\text { and creatures, including us. Unfortunately, many consider RuBisCO } \\
\text { ineffective and inefficient for its tasks. }\end{array}$ \\
\hline High Text Complexity & $\begin{array}{l}\text { RuBisCO's importance cannot be overstated. As the principle catalyst for } \\
\text { photosynthesis, it provides a fundamental method for manufacturing the } \\
\text { carbon building block necessary for life. By interacting with atmospheric } \\
\text { carbon dioxide, RuBisCO ignites a chain of biochemical reactions that } \\
\text { creates the carbohydrates, the proteins, and the fats that sustain all living } \\
\text { organisms, including us. However, it is the most inefficient and lacking } \\
\text { enzyme in primary metabolism. }\end{array}$ \\
\hline
\end{tabular}

Table 1: Example paragraphs varied according to the two levels of text complexity: high text complexity.

This study defined text complexity by focusing on whether there are casual and referential connections. In other words, the articles varied, according to text complexity, in three ways:

1. Whether the articles included more advance scientific terminology or commonplace words mixed with simpler scientific terminology,

2. Whether the simple scientific or technical explanations and definitions about the topic were present and if they were worded with scientific terminology or more commonplace words, and

3. Whether clear explanations of previous related research and findings were thoroughly presented or just minimal reference was made to them.

Each science article was made into two versions: one version was done as high text complexity (HTC) $)^{\mathrm{iii}}$ and another version was done as low text complexity (LTC) ${ }^{\mathrm{iii}}$. The versions of HTC made use of more advanced scientific terminology instead of less commonplace words, tried to avoid supplementing terminology with definitions and explanations, and limited the discussion of previous research in the article's topic. In 
contrast, the versions of LTC made more use of commonplace words than versions of HTC, supplemented terminology with explanations and definitions, and explained more thoroughly than version of HTC how previous research relates to the current research and findings. The researcher argued that, according to previous studies, people with high PK level should have an easier time comprehending the article version of HTC than readers with low PK level. This study used two versions of the original articles written as HTC and two other versions of the original article written as LTC to control text complexity. The two versions allowed for a within-subjects manipulation due to each participant receiving both text complexities (Brooks et al, 1977; McKeown et al., 1992; McNamara et al., 1996; Linderholm et al., 2000; Lin et al., 2002; Caillies et al., 2002).

The second structural facet was the presence of visuals in the article. Previous studies in education, psychology, and newspapers have shown that the impact of visuals, such as video, photos, charts, and graphs, depends primarily on how familiar people are with the text and/or using that type of visual being added to the text . In the case of children, if they were a good text reader, he or she would also be a good picture and/or graph reader (Curcio, 1987). In foreign language classes, several studies have examined the impact on learning cultural aspects and language from text both aided and not aided by video. There was a significant variation among students when picking up the information and facts from the text (Herron et al., 1999; Hanley et al., 1995). When considering text and static visuals, such as pictures, the effect depended on how much PK they had on the subject, but there was no difference seen between the PK levels when text and video are paired together (Newton, 1994; Curcio, 1987; Brooks et al., 1977; Hanley et al., 1995; Friel et al., 2001; Herron et al., 1999). 
In the literature that examined pairing up video and text, there was little significant interaction (Hanley et al., 1995; Herron et al., 1999). This study used only static visuals due to this fact and the researcher's need to simplify the variable of visuals. More specifically, the study looked at static visuals consisting of a graphical image with an overlaid informational chart or graph. The researcher called this type of visual, complex graphical elements (CGE). The manipulation of this structural facet was whether CGE are present or absent. When the article's CGE were present, they had a consistent lay out on the page with the text. The study hoped to figure out the following:

1. Whether CGE aid in text comprehension,

2. Whether there is a significant difference in their helpfulness between readers with high PK levels and readers with low PK levels, and

3. Whether there is an interaction between the CGE and text complexity.

This study used these two structural facets to see if and how they trigger both versions of text comprehension: perceived comprehension and problem-solving comprehension, while taking into account a reader's PK level (Kintsch, 1998, 2005). Comprehension was defined for this study according to Kintsch's ConstructionIntegration (C-I) model. The C-I model breaks up text comprehension according to whether an impasse forms, causing discourse comprehension to occur (Kintsch, 1998). For when discourse comprehension does happen, text comprehension has transpired, which means readers are learning and assimilation is occurring. Assimilation is the process of adding information from a text to a reader's PK. The more they learn the better they are able to understand the technical and scientific aspects of the world around them (Miller, 1998, 2004; Pardo \& Calvo, 2004). 
In today's ever-shrinking world, technology is part of almost every aspect of life, including the economy, business, education, health, and communication. This technology-based world requires people to understand the technical and scientific concepts that make it function and usable for them (Falk, Storksdieck, \& Dierking, 2007). Every day the areas of science and technology expand and change. In fact, they are two of the largest and fastest growing areas of research. The range and pace new ideas, concepts, and applications are explored is astounding. Many have found their way into the public forums, such as gene therapy, global warming, and antibiotics (Miller, 2004; Pardo \& Calvo, 2004; Kua et al., 2004; Field \& Powell, 2001). Therefore, while it is unfeasible to expect everyone to be thoroughly knowledgeable on all areas of science and technology, they should at least have a grasp on the fundamentals behind these two areas. This knowledge will give them an advantage when interacting with the world around them (Kua et al., 2004; Miller, 2004; Falk et al., 2007).Unfortunately, only a very small percentage of people in industrialized countries around the world truly understand or comprehend the findings coming out of these two areas and what they mean to them. Science literacy (SL) is the concept that defines the leading cause of the lack of knowledge or incomplete knowledge (Miller, 2004; Kua et al., 2004)

SL is a person's ability to use scientific or technical knowledge to resolve issues he or she comes across and to come up with "evidence-based conclusions." Then a person can understand scientific reading material and allow him or her to make well-informed decisions when interacting with others (Miller, 2004; Organization for Economic Cooperation and Development [OECD], 2003). Being scientifically literate also means a person can read literature, articles, and texts about the areas of science and technology. 
Jon. D. Miller believes that at a minimum a person should be able to read and understand articles within the science section of the Tuesday edition of The New York Times (1998, 2004). Others, including the researcher of this study, agree with this datum set by Miller. The media are a great source for explaining topics in science and technology outside of the area of education. That is why science journalists and the media must improve in covering these topics. The literature by Miller, Jon Durant, and others agree with this statement. In their related papers, they write that SL can best be resolved through improving how the media presents, explains, and relates the topics and research coming out of these areas (Miller, 1998, 2004; Pardo \& Calvo, 2004; Evans \& Durant, 1995).

In fact, some researchers believe the science media are partially to blame for the low count of scientifically literate people in the world. Currently, according to Miller, only about 17 percent of Americans are scientifically literate. This low percentage of the population suggests, according to some researchers, that the science media is unable to present or explain these concepts and studies in a way that the public can both understand and perceive. The media has a large impact on how the public views and understands the areas of science and technology (Norris, Phillips, \& Korpan, 2003; Kintsch 1998; Miller, 2004; Pardo \& Calvo, 2004; Field \& Powell, 2001). In the writing of a science article or report, many researchers believe there must be more emphasis placed on clearly and completely presenting the information, research, and reasoning behind it. A good writer would clearly define the concepts and then give sound contextual information about how these concepts fit together. If the audience cannot comprehend the what, how, and why of research results, then they might not understand why it is important, why it is so 
controversial, why it is so ground breaking, or why it is in conflict with other theories or research out there (Field \& Powell, 2001; Miller, 2004; Brooks et al., 1977).

This study used the two structural facets discussed earlier, taking into account each reader's PK level, to see how it might be involved in a reader's text comprehension. The study ran a fractional within-subjects experiment using a university computer laboratory. It examined the interaction between text complexity and PK, CGE and PK, and between the two structural facets to see their impact on readers' text comprehension. Each participant in this experiment received a random order of the four articles: one is a version of HTC with CGE present, another is a version of HTC with CGE absent, a third is a version of LTC with CGE present, and a fourth is a version of LTC with CGE absent. The participant only ever received one of the four versions of each original science article. Before reading any of the articles and answering questions about them, the participant answered 12 timed, questions that tested his or her PK level.

Then the participant ran through their four, timed articles, which he or she randomly viewed. After reading an article, he or she received a timed series of 12 questions corresponding to the article he or she just read. Since the study used the theory behind the construction-integration (C-I) model to define comprehension, the articles' post-reading questionnaires were broken up to give an overall idea of text comprehension. Four questions concerned recognition memory and were true and false questions. Four other questions concerned problem solving recall memory ${ }^{\text {iv }}$, which is a researcher created variable, and these required participants to go beyond just remembering information and actually perform assimilation using their schemata. The last four were statements 
concerned with a reader's perception of the science article. On a scale from 1 to 7 , the participant decided if he or she agreed or disagreed with the statement about the article.

Only after the participant completed the entire experiment, during the allotted hour, the researcher examined the participant's PK level. After the participant finished all four articles and their corresponding questionnaires, he or she answered seven, timed questions about his or her demographics. These were used to see if a correlation between education level and a reader's PK level, and reading of science magazines and a reader's PK level. The reason for this was the fact that a person's educational background and reading habits are two places a reader gains PK (Kendeou and van den Broek, 2007; Tobias, 1994).

The researcher hoped that this study could further demonstrate the effect that the text properties, page properties, and readers' characteristics have on the degree different types of readers are able to construct their text comprehension as well as problem-solve and perceive a science article. In addition, since few comprehension studies have focused on science articles, particularly online, the study might add new color and thought to where the application of text comprehension and science literacy can be examined in the future (Kintsch, 1988, 1998, 2005; Kua et al., 2004; Macedo-Rouet et al., 2003). 


\section{CHAPTER 1: LITERATURE REVIEW}

This chapter examines the literature that surrounded this study's research questions, hypotheses, and the variables involved in the experiment. However, before getting into those aspects of the study, a thorough examination must be made of the theories behind this study and the relationship between the concept of scientific literacy (SL) and the research topic viewed in terms of the science media. The literature shows that a reader's SL is at the heart of finding out what aspects of a science article aid a reader in gathering knowledge to comprehend. SL is core to understanding how factors of an article influence a reader perceives a science article's ability to aid in his or her text comprehension of a science or technology topic.

\subsection{THEORIES BEHIND THE STUDY}

This study found the foundation in two theoretical models: the ConstructionIntegration (C-I) model and the Limited Capacity Model of Motivated Mediated Message Processing (LC4MP). Both models apply to the print media for online and offline formats. Each point out the importance of taking prior knowledge $(\mathrm{PK})^{\mathrm{i}}$ into account and can examine discourse comprehension (Kintsch, 1988, 1998, 2005; Lang, 2000, 2006).

The first model defined the concept of text comprehension. Comprehension is a complex concept. There are many ways to examine and apply it. For this study, the researcher found that the theory behind Walter Kintsch's C-I model did the best job of defining text comprehension for a reader of an online science article (Kintsch, 1998, 
1998, 2005). In addition, other studies that examine text comprehension and specifically online text comprehension have used the C-I model (Singer \& Kintsch, 2001; Salmerón et al., 2006). Besides defining the leading concept in this study, the C-I model also demonstrates that the variable of reader's PK is most likely to have a significant impact on the way the article's structural facets influence a reader's text comprehension. Thus, it aided in the creation of the study's research questions and hypotheses, which are gone into more detail later (Kintsch, 1988, 1998, 2005; Salmerón et al., 2006).

The second model laid the foundation for this study's methodology (Lang, 2000, 2006). It specifically went into the creation of the message that comes out of the science or technology article. In the case of this study, the message was the article's topic, which should lead to the readers gaining knowledge. According to Lang, the success of a message depends on the media chosen for the presentation of it, its content, and the goals of the article. The study examined these aspects when the two structural facets are controlled or manipulated, and looked at in terms of each other and between readers with different PK levels. To process the message most efficiently, the three major subprocesses: encoding, storage, and retrieval, must have consideration as well. The ways these subprocesses work depends on the reader's PK level, particularly for the storage, which links the recently coded information with previous knowledge the reader has on the topic in a process known as assimilation (Lang, 2006). Thus, the design of the experiment involved the examination of each structural facet and took into account the PK levels of the participants. 


\subsubsection{CONSTRUCTION-INTEGRATION MODEL}

Walter Kintsch's Construction-Integration (C-I) model's theory often is examined as a general model of discourse comprehension (Singer \& Kintsch, 2001). Discourse is referring to the interference that builds as one is reading or taking in information. The amount of general discourse depends upon the level of PK or prior experience of the reader in the topic covered in the text. This PK or prior experience, in turn, affects the development, revisions, modifications, and editing of related schemata, which are an alternative name for the organized units of past experiences or knowledge, involved in the process of the C-I model. This occurrence is also true for graphs and charts containing text or used along with the text (Curcio, 1987; Brooks et al., 1977).

In this model, text comprehension is a kind of problem-solving, and reading is active problem-solving (Kintsch, 2005), because discourse happens when a reader needs to critically examine the information and apply it to a problem. According to Kintsch, "fluent adult reading is more akin to automatic perception than deliberate analysis (2005).” McNamara et al. (1996) seems to agree with Kintsch, calling this type of understanding a recall with reduced active processing: figuring out the meaning of the text. Kintsch created the C-I model to explain comprehension as a process that connects the ideas of a text in a coherent representation. Coherence comes about due to the two phases of the C-I model: the construction phase and the integration phase (Salmerón et al., 2006; McNamara et al., 1996; Caillies et al., 2002; Kintsch, 1988, 2005; Sanjosé et al., 2006).

The process of the model occurs in cycles. Each of these cycles occurs when the "understander," i.e. reader, considers the text that contains a specific amount of additional 
ideas or "propositions." Within each cycle, both phases of the C-I model occur (Singer \& Kintsch, 2001). The two phases complement each other and work in conjunction. During the construction phase, a network of words forms from propositions extracted from the text or article. These words relate to each other in various ways. Singer \& Kintsch use the following example:

"The spelunker dropped his pipe. He lit a match. (2001)" (Figure 1)

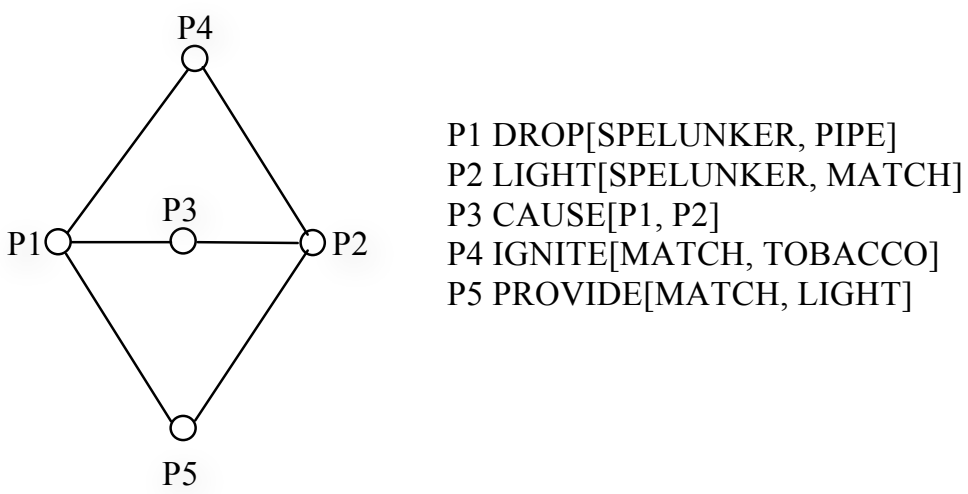

Figure 1: The C-I network of propositions used in the sequence.

According to Singer \& Kintsch, the sequence suggests that the match was to provide light to see when the spelunker could not. Figure 1 shows that there are several aspects to be considered when examining the above sequence, i.e. sentences. The first are explicit text. These aspects clearly demonstrate the occurrence and their relationship to the sequence of events and objects, for example, the proposition of dropping (P1). The second are "coherence-preserving inferences." These aspects could be a reaction to the explicit text, such as how dropping the pipe leads the spelunker to light the match (P3). Third, there are the aspects that are generalizations. These aspects are parts of the sequence that "capture the gist of the situation," such as the surroundings must have been 
dark if he needed to light the match to find the pipe (none shown in Figure 1). Lastly, the network itself has a close association of ideas that came up in the text. The example from Singer \& Kintsch is the ability of a match to both light a pipe and produce light. Some of these associations are not important to the sequence, like lighting a pipe (2001).

According to the model, when a reader takes in the knowledge his or her mind will be breaking down the sentence, as mentioned above, considering what aids in figuring out the meaning behind the text, what happened in the sequence, and what parts are not necessary for understanding. Thus, during the construction phase a reader encodes the information from the reading and places it in storage for integration with his or her other PK (Kintsch, 2005; Lang, 2006). That is why Kintsch (2005) considers text comprehension just understanding with perception, until the normal flow of information breaks down and strategic problem-solving takes over, i.e. discourse occurs. These text generated facts of information are interconnected with each other in a network like is shown in Figure 1. This leads into the second phase.

It is during the second phase in a cycle of the process that the activation of the propositions occurs. The activation spreads among the different ideas and tends to build in those network ideas that show more interconnectivity with others. Those, such as lighting a pipe, do not have high interconnectivity and will receive very little to no activation. Once finished, the next cycle starts, repeating both phases repeatedly. When the process is complete, modification of coherence happens to allow for a representation of the text in the reader's long-term memory (LTM) (Kintsch, 1988, 2005). If a coherence of the science or technology topic does happen, it will be stored in the reader's LTM for later use in activities and discussions about it or related topics. 
Put more simply, the integration phase draws from the processor's PK to fill in the gaps or resolve unclear statements from the text. The readers are doing a comparison between what they knew about the topic and the presented information in the text. This will lead to inference processing, which is more likely to encourage accurate and detailed memory storage and indexing in both short-term memory and LTM. Therefore, instead of simply being able to recognize information and perceive it in terms of itself, the processor will be able to use and apply it to new situations in the future (Caillies et al., 2002; Kintsch, 2005; McNamara et al., 1996; Kendeou \& van den Broek, 2007). Thus, the information or the message the readers are getting from the article must have a presentation that allows more people to improve their text comprehension.

\subsubsection{LIMITED CAPACITY MODEL OF MOTIVATED MEDIATED MESSAGE}

\section{PROCESSING}

Since the study strives to improve the message and the presentation of the message, the researcher chose the Limited Capacity Model of Motivated Mediated Message Processing (LC4MP) to help create this study's methodology. Annie Lang created this model to study cognitive processing of media messages, meaning the model applies to all contents, to all media, and for all goals (Lang 2000; Lang 2006). Cognition is involved in the text comprehension process, because the process requires active memory. That can be as simple as recognizing or recalling information from the text or a visual, or as complex as problem solving (Lang, 2006). The model describes the sub processes involved in information processing during exposure to a message. Such messages could include science articles, and thus, it is relevant to apply this model to this study. The sub 
processes are encoding, storage, and retrieval. All of these sub processes were taken into account in this study's examination of readers' text comprehension. The study's purpose was to change the message coming out of an online science article and to enhance text comprehension for all readers (processors) (Lang, 2000, 2006).

According to LC4MP, the processors need to allocate cognitive resources to encode information from the message into working memory, to retrieve information from LTM to help make sense of the information and message, and to store new information from the media message back into LTM. During acquisition of the media message, such as reading a science article, cognitive resources are divided amongst those three mental tasks. These resources allow them to perceive, encode, understand, and remember information (Lang, 2000, 2006). As Stephen Reed pointed out in his paper on cognitive architectures, the resources are vital to encoding verbally and visually. This study relies only on the visual encoding, and thus, all resources were focused toward the text and complex graphical elements (CGE) ${ }^{\mathrm{ii}}$, if both were present. Reading the text of an article clearly involves allocating cognitive resources to encoding the perceptual features of the text on a page or online on the screen. Thus, information is assimilated from both structural facets and integrated together by these cognitive resources (Reed, 2006; Lang, 2006). However, a substantial amount of cognitive resources are allocated to retrieving knowledge of language as well as other LTM information in order to engage in meaningful semantic processing of the text. The solution to reverse or to work with this loss of resources lies with the effectiveness of the text complexity and CGE. If the article carrying the message is effective in delivery, then the message coming from the science article will encourage and allow readers (processors) to use more of these resources 
toward retrieval and LTM storage. This result would then reduce the change of overloading the processors (Lang 2000, 2006).

However, the degree of balancing the resources is also contingent on the characteristics of a reader, including PK level. This reader characteristic has been found previously to be influential to the results of information processing of texts (Caillies et al., 2002; Kendeou \& van den Broek, 2007; Evans \& Durant, 1995; Lin, Zabrucky, Moore, 2002; Linderholm et al., 2000; McKeown et al., 1992; McNamara et al., 1996; Salmerón et al., 2006; Tobias, 1994). The researcher believed it might influence science articles too. PK is all the knowledge, experience, and exposure concerning the science topic of the text, and in this case, PK is involved in LTM. This extra information stored in LTM due to PK could make the retrieving of information processing of the science article easier, and more efficient and effective, which results in higher comprehension for individuals with high PK (Lang, 2000, 2006; Tobias, 1994; McNamara et al., 1996; Caillies et al., 2002).

Although, a reader's PK level could also be influential to the appetitive systems of a processor's motivation. For example, if a reader comes across a topic that he or she has little PK about but is curious as well, the reader will need high cognition and an equally high motivation to seek out information, including articles and research in the scientific topic area. Similar, results would exist for readers with high PK level, but since their PK level would be higher than that of the earlier reader, they should likely find it easier to reach high levels in the appetitive systems. Preferably, this study wants to encourage higher levels in the appetitive systems, since it will show an interest and positive 
perception of the science or technology topic and article (Lang, 2006; Falk et al., 2007; Miller, 2005; Evans \& Durant, 1995).

To that end, other aspects of the message, such as medium, time, and communication, need examination for their impact on cognition and motivation. A Webpage-based format of science articles utilizes at least two of the three 'multiple sensory channels' that Lang talks about in her articles (Lang, 2000, 2006). However, there is a limit on how much a processor can intake over a period of time (Lang, 2006). Consideration must be made for human behavior. Over time, it changes along with his or her reaction to stimuli. Thus, the way a processor views the message, its aspects, and its format will be constantly shifting over time and can lead to fatigue. Essentially, it influences how the processor communicates (Lang, 2000, 2006). In this study, communication was occurring between the message of the article and the reader processing it. During this interaction, comprehension difficulty occurred due to factors about the text, its visuals, or the reader (Lang, 2006; McNamara et al., 1996; Caillies et al., 2002; Kendeou \& van den Broek, 2007; Sanjosé et al., 2006). Thus, communication between the article and a reader does have an effect on the reader's memory faculties and the way he or she perceives the article's effectiveness. This study wants to avoid such difficulties by getting at the heart of the issue, which is SL (Lang, 2000, 2006; Miller, 1998, 2004; Field and Powell, 2001).

\subsection{UNDERSTANDING SCIENCE AND TECHNOLOGY LITERACY}

In the United States and most of the industrialized nations in the world, there is an agreement amongst the scientific communities about the importance of both citizens and 
leaders being scientifically literate (Miller, 2004). SL conceptually is an individual's ability to apply scientific knowledge to answer questions and to draw "evidence-based conclusions." Then a person can understand scientific reading material and allow him or her to make well-informed decisions when interacting with others and the natural world (OECD, 2003). Science communities agree about how important it is to emphasize SL among all levels in a society (Evans \& Durant, 1995; Miller, 2004). Political and legal policies up for a vote or during an election require an individual to have sufficient SL to fulfill civic responsibilities when making decisions (Miller, 2004; Pardo \& Calvo, 2004). In the areas of health and medicine, decisions require individuals to have a decent understanding of basic scientific terms and constructs as well as to generally grasp the nature of scientific inquiry; otherwise, these people risk misunderstanding and endangering themselves and those around them (Kua et al., 2004; Miller, 2004).

For example, over a decade, 1988 to 1999, John D. Miller periodically asked U.S. adults several science or technology based concepts, which had been around in the public forum and/or everyday life for some time. One of these questions was about whether “antibiotics kill both bacteria and viruses." In 1988, only 26 percent of people knew that antibiotics do not kill viruses, and in 1999, the percentage of people rose to 45 percent. While this is a significant increase, by the turn of the millennium there was still a larger portion of the U.S. population that still did not understand the basic biological concept behind medicines, particularly antibiotics, or other medical cures, such gene therapy (National Institute of Allergy and Infectious Diseases [NIAID], 2008; Miller, 2004; Field \& Powell, 2001). 
By the end of the $20^{\text {th }}$ century, only 17 percent of adults in the United States qualified as scientifically literate. This number is double what it was two decades prior, but it is still considered appalling, according to Miller, for "a democratic society that values citizen understanding of major national polices and participation in the resolution of important policy disputes (Miller, 2004; Pardo \& Calvo, 2004).” In other words, without a descent ability to grasp simple scientific concepts, the public will never fully understand the ideas or products created by research. They will also be unable to debate accurately and efficiently them with their peers or vote on policies involving their futures and their children's futures. This inability has also led to some misconceptions on what a new research area or product of science and/or technology can do for the general public (Kua et al., 2004; Miller, 2004; Pardo \& Calvo, 2004).

This lack of scientific understanding exists not simply due to being uniformed, but also because of misconceptions in people's PK (Kua et al, 2004; Kendeou \& van den Broek, 2007). The above 1988 and 1999 survey of the U.S. population by Miller is an example of a misconception by most Americans who assume antibiotics are a cure all answer. Therefore, they use it for many types of illnesses, whether or not bacteria caused it. As a result, strands of microbial came into existence and/or become resistant to some antibiotics. With more dangerous and deadly bacteria out there, health issues have become worse and more numerous (Miller, 2004; NIAID, 2008). Therefore, while it is true not knowing pieces of information can be detrimental to SL, holding on to incorrect or misconstrued facts and constructs can be just as bad, if not worse (McNamara et al., 1996; Miller, 2004). 
Another way to look at SL is through its operational terms. It is a subset of knowledge (the cognitive dimension of public perceptions of science (PPS) ${ }^{\mathrm{v}}$ of the "know-what" type. PPS is the public's attitudes toward scientific research and the results or concepts produced. Knowledge also is a measurable variable of public understanding of science (PUS). Thus, a person's ability and knowledge in the areas of science and technology allow him or her to understand the technical terminology behind the presented material. Understanding then influences how the person perceives the topic and its presentation. This interaction between people's attitudes and their perception is the core definition of PUS. The concept of SL has changed how researchers and the media approach the public's attitude toward science (Pardo \& Calvo, 2004; Miller, 2004). It has changed further depending on the format the media uses to present the science and technology topics.

There are plenty of media formats: television, newspapers, magazines, and the Internet. Each is trying to present, to explain, and to examine the information coming from the areas of science and technology. According to Horrigan's Pew Internet and American Life Project report (2006), television is the most cited primary source for science information and news at 41 percent. Second is the Internet at 20 percent; and newspapers and magazines are primarily relied on by 14 percent of the U.S. population. Therefore, there are plenty of sources of information for people to utilize.

In several studies, which examined PUS and/or PPS, they found that the U.S. population thinks both research and the advancements in science have improved the world; 80 percent of US adults in both a 1957 National Association for Science Writers (NASW) study and Miller's 1997 and 1999 Science and Engineering Indicators studies 
found similar results (2004). The Pew Internet Report when surveying Internet users also found similar findings (Horrigan, 2006).

However, the Science and Engineering Indicators 2000 found that the public's knowledge on new scientific discoveries and comfort level with them was very low. Of those that said they were interested in the areas of science and technology, only 17 percent considered themselves well informed. Interestingly, this number matches Miller's findings on the proportion of the U.S. population considered scientifically literate. About 30 percent of those interested thought they were "poorly informed."

This means that while people are enthusiastic, they do lack understanding and have concerns about scientific advancement. They are aware of potential risks as well as the concept of credibility that needs consideration when accepting and questioning research. Yet, they do not know how to tell when to accept and when to question. They require a somewhat objective outside person, i.e. a science journalist, to aid them. Someone can lay everything out and help them make connections (Miller, 1998, 2004; Pardo \& Calvo, 2004; Field \& Powell, 2004). In Field \& Powell's article, they talk about the findings of several surveys taken in the late 1990s and early 2000s. The findings found that while people were interested, they were also wary of the scientific findings because of possible bias of the researchers as well as possible dangers that could come from the research. Not all these concerns find foundation based on religious beliefs. Thus, there is both curiosity and a willingness to inquire by the U.S. population on science and technology topics. It is finding a method that is both correct and efficient for reaching at least a majority of people. That is the goal of the media, and particularly for the scientific topics, it is true for the science media and its journalists (Field \& Powell, 2004). 


\subsection{SCIENCE MEDIA FAILINGS}

Today's media struggles to inform the public about topics and research in the areas of science and technology for various reasons, including a decrease in coverage and a poor job of writing. According to a media poll by the Science and Engineering Indicators, 52 percent of journalists that were polled say, "the news media does not cover science because they are interested in instant answers and short-term results." Obviously, scientific research often cannot give this sort of story, because research is ongoing and often theory-based. All the time the areas of science and engineering are in flux with new results, ideas, theories, and solutions coming in and either adding to or replacing current ones. So one issue has to do with making the science media realize how vital their role is in overcoming the issues of SL (Pardo \& Calvo, 2004; Miller, 2004; Field \& Powell, 2001; Brooks et al., 1977). The researcher hoped that this study could aid to that end through showing how different structural facets can affect readers' comprehension. The science media need to be responsible for helping the public to re-evaluate and learn about the plethora of research and knowledge coming out of the areas of science and technology (Kua et al., 2004).

Of course, the larger issue comes from the writing and reporting of their science journalists. A good writer should be able to thoroughly describe the concepts behind a scientific or technological topic, and then provide the connections between them, so that his or her readers can understand what is going on in this field of research. Even if science media coverage improves, the quality of the writing must still be examined (Brooks et al., 1977; Norris et al., 2003). These journalists must work on improving their articles by clearly organizing, explaining, and presenting the facts of science, the research 
methods of science, and the sociology of science. The facts of science are the results and ideas discovered or posed previously as possible answers. The research methods of science are the methods for operating on a daily basis as well as the scientific method used to come up with hypotheses and test them. The sociology of science are the procedures that the science community runs on for funding, promoting theories and ideas, and the way they are judged before either being accepted or rejected by the rest of the science community (Kua et al., 2004).

In doing so, they can involve the science media's audience in the "puzzle-solving of the technical topics," which will encourage them to use their schemata and assimilate the new information into their PK. The science journalists need to give their audience the concepts with supportive reasoning of the research behind it or by posing questions about the findings (Kua et al., 2004; Brooks et al., 1977). Accomplishing all of this in a clear and effective way will lead to improvements in both the PUS and PPS (Pardo \& Calvo, 2004; Evans \& Durant, 1995; Falk et al., 2007). Thus, text comprehension, according to Kintsch, would be successful. The individual would be able to not only recognize and recall information, but also perform assimilation when discourse occurs. The reader should be able to draw upon his or her schemata to combine their PK with the information from the text, and thus, follow Jean Piaget's work (Brooks et al., 1977; Singer \& Kintsch, 2001). Piaget's work is about a child learning and remembering what he or she read. Thus, the child must have some related knowledge previously. This combining of new information with his or her PK is assimilation (Brooks et al., 1977; Tobias, 1994). Yet, similar findings for adults occur when an impasse forms (Kintsch, 1998, 2005) 
Research done by John Durant and his colleagues has shown how knowledge about an area or areas of science is important in differentiating attitudes toward diverse types of science and technology areas. Other studies have examined other variables that may explain and have more impact on people's attitudes toward science. Among these postulated reasons are putting trust in the regulator and trust in "media coverage of technoscientifc issues." If media coverage is affecting the attitudes of the general public toward science, thus impacting PUS, then what is the media doing wrong (Pardo \& Calvo, 2004; Evans \& Durant, 1995; Falk et al., 2007)? To answer this question, this study will examine the structural facets and PK that could affect text comprehension as well as the concept of text comprehension.

\subsection{TWO STRUCTURAL FACETS OF AN ONLINE SCIENCE ARTICLE}

Both the C-I model and the LC4MP point out that comprehension comes about as a reaction to some sort of stimulus (Kintsch, 1988, 1998, 2005; Lang, 2000, 2006). In the case of this study, that was the reading of an online science article. A processor, i.e. reader, visually encoded information from the article (Lang, 2000, 2006; Reed, 2006). However, it had many factors, including text properties and page properties. Thus, to narrow down what the study was examining and to simplify the number of stimuli, there were only two, narrowed down facets of the text's structure, which the researcher called structural facets. For this study, the two structural facets were text complexity and the presence of complex graphical elements $(\mathrm{CGE})^{\mathrm{ii}}$. The rest of the factors were controlled through consistent layout and length, not showing the origin of the article, etc. 


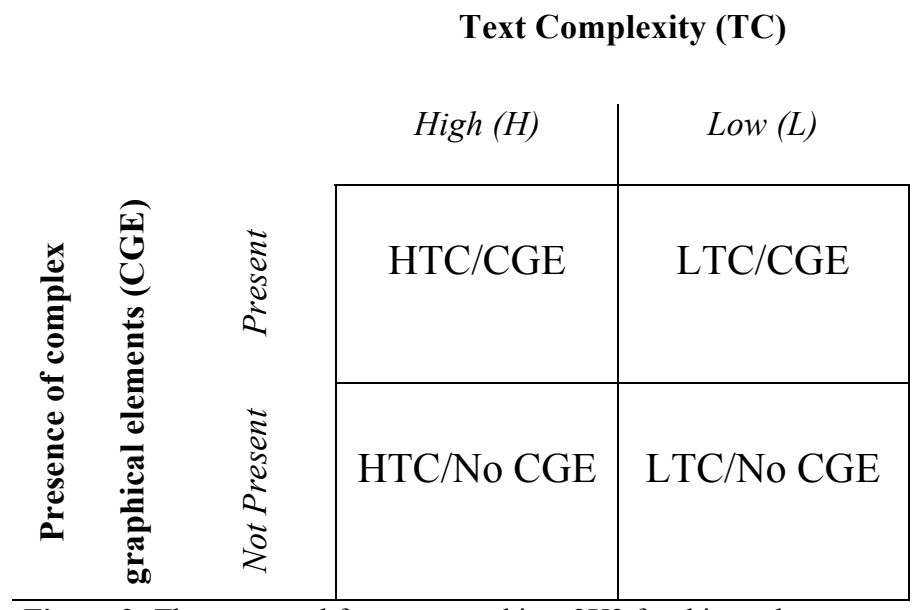

Figure 2: The structural facets crossed in a $2 \mathrm{X} 2$ for this study.

These two structural facets were part of every possible article a participant received and each article topic had one of four combinations (Figure 2). Both of the chosen structural facets had been shown in previous studies to specifically or generally have some effect on text comprehension in the areas of education, newspapers, and psychology. In fact, visuals like charts and graphs required a reader to have a good ability to read and to understand text in the additional visuals (Friel, Curcio, \& Bright, 2001; Newton, 1994; Curcio, 1987). They were controlled as mentioned in their own sections below.

\subsubsection{TEXT COMPLEXITY}

Text complexity refers to the usage of the technical area's terminology as well as the overall coherence of the text. This is mostly dependent on how the writer chooses to organize and describe the topic. They might use terminology from that field of scientific study (McNamara et al., 1996; Caillies et al., 2002). They could also use or not use casual 
and referential connections, and the writer could choose to organize of the text in a way that the reader easily understands or that makes the text have a less clear flow, i.e. less coherent (Linderholm et al., 2000; McNamara et al., 1996; Kendeou \& van den Broek, 2007)

Casual and referential connections refer back to the presence of inferential process. When there is enough casual inference present in a text, the creation of coherent mental representations occurs easily, aiding in text comprehension. This also means that the text structure exists in a way that makes it more explicit, so that more connections both casual and referential exist. The more of them, the easier it should be for a reader to understand even if they have little to no exposure to the topic (Linderholm et al., 2000). Thus, a reader can focus on integrating new ideas from the text with their current level of PK and worry less about translating (Macedo-Rouet et al., 2003; Caillies et al., 2002; Lin et al., 2002; Yarros, 2006; McNamara et al., 1996; Kendeou \& Broek, 2007; McKeown et al., 1992; Linderholm et al., 2000).

However, some studies done on science textbooks have found that the reaction to these different complexities affects comprehension according to the PK level of the reader. As mentioned before, $\mathrm{PK}$ is a variable of an individual's knowledge taken into account when considering comprehension, because any knowledge, experience, or exposure on the topic will have some impact on the stimuli's effect on comprehension (McNamara et al., 1996; Lindholm et al., 2000; Macedo-Rouet et al., 2003, Kintsch, 1998). McNamara and colleagues' paper on school aged people and science textbooks found that students with lower PK in the area of science tended to be more able to comprehend and retain more information with more coherent or less complex textbooks. 
This was not true for those with higher PK levels. The more knowledgeable students would lose interest in the text, because of its simplicity. It was the active processing they lacked, which is required for full comprehension to occur (McNamara et al., 1996).

Reversely, when both groups received textbooks that were less coherent or more complex, the students with higher PK levels did much better and active processing was in full swing, while students with lower PK levels struggled and often became fatigued. The complexity or coherence affected the ability of a person to recall, recognize, and comprehend what he or she had read. (Macedo-Rouet et al., 2003; McNamara et al., 1996; Kintsch, 1998; Caillies et al., 2002; Lin et al., 2002; Kendeou \& van den Broek, 2007; Norris et al., 2003; Tobias, 1994). However, text complexity does not only affect the text of an article. It also applies to the visuals, such as charts and graphs. Similar to the text of an article, reading comprehension of graphs and charts is dependent upon a reader's PK. It requires explanation, i.e. casual or referential connections, for those who do not have a high enough level of experience and/or knowledge (Brooks et al., 1977; McKeown et al., 1992; McNamara et al., 1996; Linderholm et al., 2000; Lin et al., 2002; Caillies et al., 2002).

This study defined text complexity by focusing on whether there are casual and referential connections (Table 1). In other words, the articles varied in three ways:

1. Whether the articles included more advance scientific terminology or commonplace words mixed with simpler scientific terminology,

2. Whether the simple scientific or technical explanations and definitions about the topic were present and if they were worded with scientific terminology or more commonplace words, and 
3. Whether clear explanations of previous related research and findings were thoroughly present or just minimal reference was made to them.

The researcher argued that, according to previous studies, people with more PK should have an easier time comprehending the text as high text complexity (HTC) ${ }^{\text {iii }}$ than readers with less PK and vice versa. In this study, making each of the four original articles into two versions controlled text complexity: two versions of HTC and two versions of low text complexity (LTC) ${ }^{\text {iii }}$. Each participant received a random order of two articles versions of HTC and two versions of LTC, but never getting more than one version of any of the four original science articles (Brooks et al., 1977; McKeown et al., 1992; McNamara et al., 1996; Linderholm et al., 2000; Lin et al., 2002; Caillies et al., 2002).

\subsubsection{COMPLEX GRAPHICAL ELEMENTS}

The other structural facet was the visuals, which referred to the additional material supplied along with the text to aid a reader in better understanding the concepts and topic. There are many variety of visuals, including pictures, charts, graphs, and video. In the online format, all can and are used. However, since their impact and complexity varies, this study focused on the static type, which the research called complex graphical elements (CGE) $)^{\mathrm{ii}}$. These charts and graphs supplemented and summarized, while also making use of images or graphical representations along with the numbers and text of the graph or chart. The reasons for choosing this visual were three-fold.

First, the researcher found through previous research and observation that graphs and charts are often utilized in science and technology writing to summarize information or to 
present it in a new way (Long, 1995; Kua et al., 2004; Macedo-Rouet et al., 2003).

Second, there was a limited amount of space both on a print page and on a Webpage, so if a journalist or communicator wanted to limit the number of times a reader has to click a link or turn the page, a doubled up visual with both chart or graph and images would help. Such a combination could be a graph or chart overlaid on top of a related background image or includes demonstration, graphical representation pictures within the chart or graph. Third, explanatory images placed alongside or underneath can assist summarizing charts and graphs.

Each of the four original articles contained CGE with the text. Only two versions of the original article made use of them: one article for each text complexity level. In terms of a participant, two of the four articles he or she received contained CGE. This procedure was to test to see three facts. First, it showed if the presence of CGE affected the reader's text comprehension. In David and Kang's study, they found that visuals do affect learning from text in a newspaper, and in fact, can be just as effective as 'highimagery language' (1998).

Second, having half the articles with CGE and the other half without allowed the study to see if there was a difference in how different PK level readers are affected. Previous studies in education, newspapers, and computer usage have shown an impact from visuals, such as photos, charts, and graphs. According to some, the effect depends primarily on how familiar people are with the text and/or using that type of additional visual (David \& Kang, 1998; Macedo-Rouet et al., 2003; Adaval et al., 2007; Herron et al., 1999; Brooks et al., 1977; Curcio, 1987; Newton, 1994; Friel et al., 2001; Reed, 2006). 
Third, it demonstrated if there was an interaction between the two structural facets of

the science article. Since both words and visuals use the visual encoding, there should be an integration of any gathered schemata. This integration means an interaction is more than likely occurring between the two structural facets (Lang, 2006; David \& Kang, 1998; Macedo-Rouet et al., 2003; Adaval et al., 2007; Herron et al., 1999; Brooks et al., 1977; Curcio, 1987; Newton, 1994; Friel et al., 2001; Reed, 2006).

For children, if he or she were a good text reader, then the child would often also be a good picture, graph, and/or chart reader. The question is whether this holds true in a media setting like an online science article (Newton, 1994; Curcio, 1987; Brooks et al., 1977; Friel et al., 2001; Herron et al., 1999). In addition, while there seem to be little significant interaction between the PK level and video, there definitely appears to be interaction between low PK level and pictures in the area of education. In fact, Reed mentions in relation to science that the Mayer's Multimedia Theory states that students learn better when both pictures and words are present and on the same page. The theory suggests better coherence occurs, but, as other researchers have found, there are individual differences; for example, prior knowledge, can an influence how much and in what way the picture or visual effects learning and comprehension (Reed, 2006).

\subsection{COMPREHENSION DEFINED AND DIVIDED}

At the very corner stone of this study is the concept of comprehension or understanding. By itself, comprehension is a broad term with many impacting variables, including a reader's PK, a reader's motivation, and the text complexity or the text 
coherence (McNamara et al., 1996; Kendeou \& van den Broek, 2007; Caillies et al., 2002; Sanjosé et al., 2006; Salmerón et al., 2006; Lin et al., 2002). According to Miller, understanding can be defined at the basic level as "the idea of what something means" to a very technical level of "understanding a concept or construct in the full context of its field." It is this technical understanding that Miller believes a citizen needs to fulfill his or her civic responsibilities. Miller, who is a researcher in the area of biomedical communication, suggests the definition of scientific understanding, at least in terms of SL, should be according to a person's ability to sufficiently read and comprehend the Tuesday science section of The New York Times. Among many communication researchers there is a broad agreement with the idea that The New York Times level of understanding is a good basis for SL, despite a split between researchers on operational definitions of understanding (Miller, 2004).

This study uses Kintsch's operational definitions from the theory behind the Construction-Integration (C-I) model to define text comprehension. In terms of psychology research, Kintsch has differentiated between understanding with perception, which can be as simple as perceiving, and understanding with problem-solving. Both described as a process of constraint satisfaction (Kintsch, 1988, 1998, 2005).

'Understanding with perception' is when a person reacts to a particular environment or situation by either an "overt action" or mental consideration before acting. A person's knowledge and goals decide the result. The processes are unconscious and little cognitive resources or schemata are required (Kintsch, 1998). This is similar to the idea of recognition memory, since it does not require active processing (McNamara et al., 1996). 
When understanding or comprehension pairs up with problem-solving, the situation and reactions are similar. However, since to the constraints of satisfactions are through complex procedures instead of the environment or person, the mental processes are consciously controlled. While they are different in process, it is when the two types of comprehension occur that truly differentiates them from one another.

People usually use 'understanding with perception,' but when an impasse forms, they must problem solve to repair the process (Kintsch, 1998). Even in this limited definition, many factors affect comprehension. Both types of understanding are a process of constraint satisfaction, which are certain conditions that must be satisfied for processing, in this case comprehension, to occur. For this study, both versions of Kintsch's comprehension find use to give a full idea of an individual's ability to comprehend what is happening in the text (Kintsch, 1998, 2005). According to Kintsch (2005), text comprehension is a cross between "comprehending a problem" and "comprehending a perceptual scene." Text comprehension is then a composite of memory and perception.

Memory examined the encoding, storing, and retrieving of information from a processor's memory. The processor was a reader in this study, since the focus was on visual and text setting (Kintsch, 1998; Salmerón et al., 2006; McNamara et al., 1996; Lang, 2006; Kendeou \& van den Broek, 2007; Caillies et al., 2002). As such, it was viewed as a problem solving, since reading is active problem solving when interference occurs. This occurrence is when normal flow breaks down in the gathering of information and the reader must integrate the new knowledge with the PK they have on the topic matter (Kintsch, 1998, 2005). This combining is assimilation in the area of education. During normal processing, recognition memory and basic recall memory will be the 
providers of gathered knowledge. However, once interference due to an impasse occurs, the problem-solving aspect begins and a person's schemata start working to figure out the propositions formed in a sequence or the text and how they relate to the knowledge he or she already has on the topic (Kintsch, 1998; Lang, 2006; Brooks et al., 1977).

Perception falls into the other primary concept of understanding. As mentioned previously, perception defines an operationalized version of comprehension or understanding. It does not necessarily lead to action, but it is beneficial in figuring out how well a person understands the language of the text (Kintsch, 1998). Each of these variables: recognition memory, problem-solving recall memory, and perception of the online science article, is interrelated to one another in terms of the basic processes involved in reading and memory.

Outside of memory and perception is prior knowledge $(\mathrm{PK})^{\mathrm{i}}$. PK is an independent variable that is a mediator between comprehension and the different structural facets of the science articles (Figure 3 and Figure 4). The concept of PK refers to any previous experience, education, exposure, or knowledge a person gained previously that relates to the presented topic in the message, or in the case of this study, the article. For example, the researcher would need to take into account any knowledge or experience about astronomy, astrological engineering, or even physics of a participant when examining a score of a questionnaire about an article on the Pluto losing its planetary status (Soter, 2007, Gunter, 2000). 


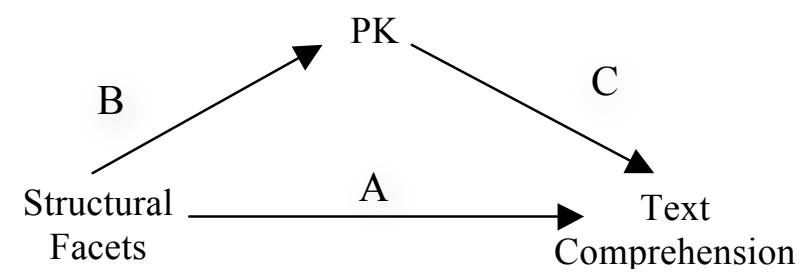

Figure 3: This study's research questions modeled as a chart.

It affects both how the person's memory operates as well as how he or she perceives the way an article presents and explains the science or technology topic. The higher the level of PK the more the reader can skip the basic explanations behind complex concepts and topics in an article, understanding more scientific phrasing, and probably is more familiar with previous research. The vice versa is also true; the lower the level of prior knowledge the more help in basic explanations are required to understand complex concepts and topics in an article, the less scientific phrasing he or she will likely understand, and the less informed the reader will be on the area of research. This idea of looking at people's PK is a vital idea covered in several literatures dealing with comprehension (Caillies et al., 2002; McNamara et al., 1996; Kendeou \& van den Broek, 2007; Sanjosé et al., 2006; Salmerón et al., 2006; Reed, 2006; Curcio, 1987).

Supposedly, as the article gets more complex in text, the readers at different PK levels: high and low, react differently. Thus, some studies have proposed that text structure and text coherence or text complexity can cause a shift in text comprehension. When testing students at middle school, high school, and college level with different science textbooks, some studies found that students with more PK did better with HTC or less coherent texts. The students with less PK were able to understand and remember more when the science textbooks were LTC or more coherent. The same is true for 
technical texts that aided people in performing different commands in computer programs (Salmerón et al., 2006; Lin et al., 2002; Caillies et al., 2002; McNamara et al., 1996;

Kendeou \& van den Broek, 2007).

Another way to look at it is by the fact that when people read text or messages, they automatically come in with a certain level of knowledge about the presented content, whether that is zero or higher. Having a certain level of PK means that those readers with high PK levels should be more familiar with the presented information and they can make jumps in logic that readers with low PK levels might not be able to do. Thus, they may have less success with problem-solving recall problems, which require a person to use his or her PK, and infer missing information (Kintsch, 1988, 1998, 2005; Lang, 2006; Salmerón et al., 2006). Hypothesis 1 examined this idea.

H1: There is significant interaction between prior knowledge and text complexity, such that readers with low prior knowledge will have higher text comprehension with low text complexity and readers with high prior knowledge will have higher text comprehension with high text complexity.

Factors of both the reading material and the reader affect comprehension in the areas of education and psychology (Kintsch, 1998, 2005). In fact, Mayer's Multimedia Theory suggests that in the area of science education students learn better when both words and pictures or visuals are present (Reed, 2006). That is why this study has decided to look at not only text complexity, but also complex graphical elements (CGE) ${ }^{\mathrm{iii}}$. In the area of education, several studies done on beginning readers, young adults, and college age 
adults examine the impact of visuals. In Hanley et al. study of students learning French (1995), the helpfulness of static pictures depended on the familiarity and ability to read the text. Thus, the more PK a reader has in reading as well on the topic affects whether a static visual aids or hinders comprehension (Reed, 2006). A similar assumption is true for graphs. According to Friel et al. (2001), graphs read ability is dependent on the "situational knowledge" of a reader, which affects how he or she interprets and perceives the graphs relationship to the text or chart. Since a reader with low PK level might lack the necessary background, he or she most likely might struggle to grasp the context or application. Yet, when compared to those who had only text and no visual, low PK level students did better when the visuals were present (Friel et al., 2001), while readers with high PK levels showed no difference whether or not pictures and text were present together. To simplify this study, it used only static visuals consisting of graph or chart overlaid on top of or consisting of graphical representations. Hypothesis 2 examined similar assumptions to those found in the area of education.

H2: There is significant interaction between prior knowledge and the presence of complex graphical elements, such that readers with low prior knowledge level will have higher text comprehension when complex graphical elements are present, but readers with high prior knowledge level will see no significant difference in their text comprehension whether or not complex graphical elements are present.

The study examined the relationship between the structural facets and text comprehension as well as a relationship between actual comprehension and a reader's 
perception of the article's ability to cause text comprehension. According to the C-I

model, the study assumed text comprehension was primarily a result of mental processing but included an impact from perception. The model also concedes that a measurement must be made by the independent variable of PK. The measured variables standing in for the concept of text comprehension are (1) recognition memory, (2) problem-solving recall memory, and (3) perception of an online science article (Figure 3) and talked about in more detail in this study's research questions (Kintsch, 1998, 2005).

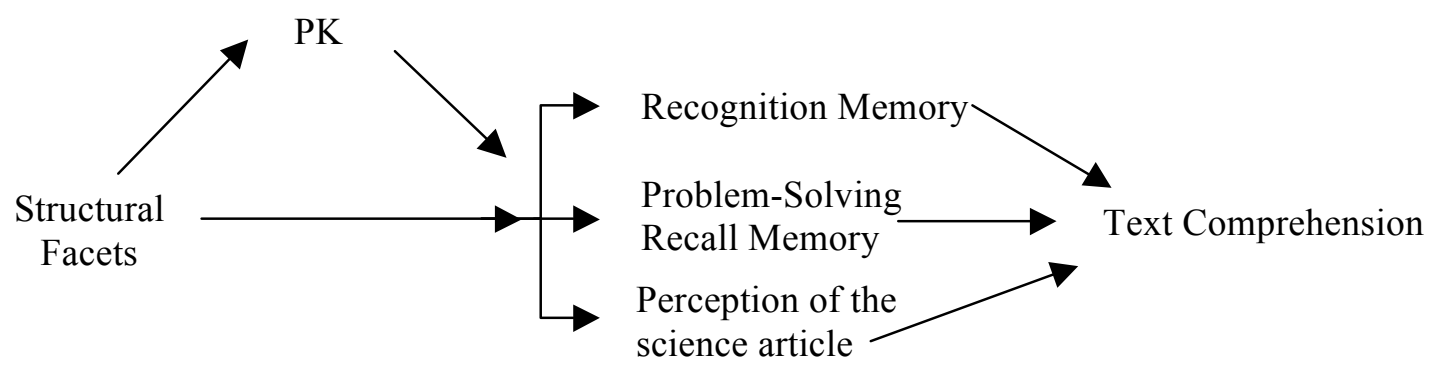

Figure 4: The research questions' model with the three parts of text comprehension.

\subsubsection{RECOGNITION MEMORY}

Many theories have explored recognition. Each examined different aspects or applications of recognition: word recognition, time of recognition, sentence recognition, etc (Caillies et al., 2002; Shapiro, 1994). Recognition memory is very good when reading sentences from a text, but there are different ways a reader recognizes what he or she viewed. A reader might recall verbatim from the text, paraphrase it, make a plausible inference, or make an overview of the idea (Singer \& Kintsch, 2001; Brooks et al., 1977). Since it was the ideas behind the article's topic that this study wanted to get across to the readers, sentence recognition and perhaps recognizing 'key' words were the types of 
recognition examined (Caillies et al., 2002; Shapiro, 1994). Recognition is also one of the more sensitive measurements of memory. The reason for the high sensitivity is due to the text containing several cues to help the reader find them. Thus, at the most basic level of reading, the implementation of recognition is during memory encoding (Lang, 2000, 2006; Shapiro, 1994).

In the C-I model, recognition would happen during the construction phase of each cycle. The new information encodes and stores in short-term (active) memory (Kintsch, 1988, 1998, 2005). Without active processing and before an impasse forms, readers will be able to at least recognize concepts and terminology that appeared in the article (Kintsch, 1998, 2005). The C-I model uses episodic memory to represent a person's active memory when reading. By structuring the memory representation this way, a reader increases his or her chances of recognizing sentences or recalling information from an article (Caillies et al., 2002).

In Lang's model $(2000,2006)$, the reader, i.e. processor, of the message will be recognizing details about the topic: who, what, when, where, why, and how. However, in both LC4MP and the C-I model, this type of memory does not demonstrate complete comprehension of the science topic. It relies too heavily on mental stimuli and familiarity. The typical measurement of recognition is true-false questions, which assumes that memory is either there or not there (Shapiro, 1994). Recognition does not have enough integration between new knowledge and PK, which requires active processing (McNamara et al., 1996). Here is where the other steps of memory impact and the second phase of the C-I model would begin (Kintsch, 1988, 1998, 2005). 


\subsubsection{PROBLEM-SOLVING RECALL MEMORY}

Problem-solving recall memory ${ }^{\mathrm{ii}}$ was a researcher created variable that crosses the concept of recall memory and the concept of problem solving. Recall memory is the ability of a person to identify whether a piece of information is present in an article or actively confirms parts of the information, such as the reasoning behind a research procedure (Brooks et al., 1977; McNamara et al., 1996). The problem-solving side of the variable goes a step further and requires the readers to take what they recall and apply it to a problem. For example, an article on Pluto losing its planetary status require a person to answer whether characteristics given belong to a planet or just an asteroid, according to the given information and what they read in the article (Soter, 2007; Caillies et al., 2002; Kintsch, 1998, 2005).

There are two reasons for this crossbreeding of two concepts used previously in studies. First, recognition and perception were not specific enough in terms of defining readers' understanding of a science article's topic. Even Kintsch's C-I model emphasizes the importance of problem solving (Kintsch, 1998, 2005). Second, whenever comprehension was used as a variable in science textbook analysis, it was made with the assumption that a large portion due to problem solving going on, but never defined how problem solving can be discovered for a purely text orientated task. Third, since we are moving away from the print format, where most of previous research that used the C-I model is located, a new type of variable is needed to take advantage of the Webpagebased format and layout, and take into account that visual and text integration needed for potentially gathering new knowledge to prove full text comprehension. 


\subsubsection{THE PERCEPTION OF AN ONLINE SCIENCE ARTICLE}

Perception is part of the other version of Kintsch's definition for text comprehension. Unlike the other two dependent variables, this one has no direct connection to memory. It is, however, a version of comprehension. This version of understanding comes in two forms: the simple form of perceiving that does not require action and the understand version that requires specific action. In terms of this study, the understand version was used. It occurs when an issue between an object and its context ensues. For the study, the object was the online science article and the context was its ability to present the science

or technology topic in a way that affects how well a reader comprehends (Kintsch, 1998). By examining a person's perception of the science article, the study gained an understanding about the attitude and interest of the reader. Both affect the reader's perception. Several other researchers' studies have found similar results (Miller, 1998, 2004; Pardo \& Calvo, 2004; Norris et al., 2003).

However, according to Tobias's (1994) analysis of previous research done involving interest, prior knowledge, and learning in the area of education, is mixed on conclusions involving whether there is a significant correlation between prior knowledge and comprehension as well as prior knowledge and interest. Yet, he concludes there is a stronger 'linear relationship' between prior knowledge and interest, which directly relates to a reader's perception. Thus, the researcher came up with the following hypothesis 3:

H3: There will be a stronger correlation between prior knowledge and the perception of an online science article compared to any correlation between actual text comprehension and the perception of an online science article. 
According to Miller (1998, 2004), Norris et al. (2003), Tobias (1994) and Pardo \& Calvo (2004), this should reveal the attitudes of a person toward science and technology topics covered. Just as much as the other type of understanding, it has an impact on the willingness of a person to read science articles. The hypothesis had to do with the fact that perception is more dependent on the fact of ease ability to read through a text and interest in the topic material rather than a person's ability to learn the information anew.

Despite introducing the same articles to people both with and without in-depth experience or knowledge about the topic, the researcher assumed that the bias toward or against science will be present regardless. Thus, the PK level should have more of an effect on perception than a participant's ability to learn and apply what he or she learned (Evans \& Durant, 1995; Falk et al., 2007; Miller, 1998, 2004; Pardo \& Calvo, 2004).

For this study, recognition memory, problem-solving recall memory, and perception of a science article were touched upon by being stimuli to see the effect, being measured to see the influence, or being controlled to eliminate impact, respectfully. The next section describes how they are involved in the study's research questions.

\subsection{THE INFLUENCE OF THE STRUCTURAL FACETS OF AN ONLINE SCIENCE ARTICLE ON A READER'S TEXT COMPREHENSION}

This research looks at text comprehension in the science media, specifically for an online science article. The focus was on the concept of comprehension acquired through knowledge gained and knowledge applied due to specific structural facets of a science article. The concept or construct of text comprehension came about, because of the 
author's observations and due to the amount of background literature on the public's attitude or interest in science and their connection to comprehension. The focus was on the online science article's structural facets of text complexity and the presence of CGE. These were gone into in more detail in the methodology section. The overall research question that this study wanted to answer (Figure 3) is the following:

RQ1: How do the structural facets of an online science article affect text comprehension?

To answer this research question, the study ran a within-subjects experiment. It examined the interactions between the independent and the dependent variables. Each interaction has its own research question:

RQ2: How does a reader's prior knowledge level affect the relationship between the text complexity of an online science article and the reader's text comprehension?

Research question 2, as shown by the path BC (Figure 3 and Figure 4), required an examination of hypothesis 1, since it focused on the interaction between PK and text complexity. Any examination of significant interaction and main effects in the experiment would demonstrate how significant they are and if they vary between readers with different PK levels. Research question 3 went one-step further and took into account the presence of CGE: 
RQ3: Does an interaction exist between text complexity and complex graphical elements of an online science article when examining a reader's text comprehension, and how does it vary between readers with different prior knowledge levels?

While the types of structural facets examined here could be in the print format, this study will focus on the online version. The primary reason for this decision was that the Internet has become a powerful medium for information and newsgathering. According to a 2006 Pew Internet Report, 20 percent of Americans who use the Internet for their primary source for science news and information have various reasons to do so, including it is convenient for them, they believe it is more accurate, and/or they believe the information online cannot be found anywhere else (Horrigan, 2006). At the same time, the Internet is steadily being used more often for producing and delivering news by news organizations or those trying to get information out to the public (Macedo-Rouet et al., 2003). For example, disease interest groups, like the Juvenile Diabetes Foundation, have been posting a steady flow of news releases on DNA research (Miller, 2004). According Macedo-Rouet et al., magazines are quickly following the transition into a digital format and offering an online version. This new medium gives science journalism and science communication a 'new space' from which to build upon as well as new tools to use for a more in-depth report or a different presentation option (2003). 


\section{CHAPTER 2: METHODOLOGY}

This chapter focuses on the methodology used for the experiment. This examination includes looking at the design of the experiment, running through the procedures for it, and breaking down the measured, controlled, and manipulated variables varied according to the leading research questions of the study. Before going into that, this section examines the study's general methodology.

\subsection{WEBPAGE-BASED EXPERIMENT}

The methodology for this study was a manipulated Webpage-based experiment, which utilized the theory behind the Limited Capacity Model of Motivated Mediated Message Processing (LC4MP) and used the current format utilized by science magazine Web sites, such as Scientific American and Science. The reason for an experiment method was due to two aspects of an experiment. First, it is the most efficient way "to test a relationship or a set of relationships between two or more quantifiable variables." This study is interested in seeing the relationship, the main effects, and the interactions between specific structural facets of an article: text complexity and complex graphical elements $(\mathrm{CGE})^{\mathrm{ii}}$, the reader's prior knowledge $(\mathrm{PK})^{\mathrm{i}}$, and the concept of text comprehension. Second, an experiment often includes a manipulation and compares the results of situations both with and without the manipulation. Each article had a version written for both levels of text complexity and for both text complexity levels the CGE of 
the original article was present and absent. This study then examined the individual impact along with the combined impact of the structural facets.

The researcher chose four science articles from online Web sites and all were on different topics, initially about the same length, and contained text and at least one CGE. The format and layout controlled articles are manipulated by making them into four versions. One version of the text was high text complexity (HTC) $)^{\mathrm{iii}}$ and the original article's CGE were present. Another version of the text was HTC and the original article's CGE were absent. A third version of the text was low text complexity (LTC) ${ }^{\mathrm{iii}}$ and the original article's CGE were present. A fourth version of the text was LTC and the original article's CGE were absent. The structural facets of text complexity and the presence of the CGE were the stimuli for text comprehension (Gunter, 2000). The best place to see their impact is in an online format.

The researcher chose the Webpage-base format due to the fact more people are going online for science news and information over time (Horrigan, 2006). Using this format was also due to the growing popularity to use it and its great many new tools for publishing science information and news. In fact, interest groups, private organizations, and the news media are taking advantage of this medium (Macedo-Rouet et al., 2003; Miller, 2004). According to the Pew Internet Report by Horrigan (2006), the Internet is the second leading medium for supplying the information that people seek for many personal and professional reasons. Thus, if people want to go to there and they are going there, then this format needs to be examined first in terms text comprehension of these science and technology articles. 
Since the study occurred in a controlled laboratory with manipulated format and layout structures, which were made consistent, the study should be able to avoid the issue of bias toward a particular magazine and the impact of various formats and layouts. The study also took into account PK through timed, pre-test questionnaires, based off previously used tests (Miller, 2004; McNamara et al., 1996; Salmerón et al., 2006; Kendeou et al., 2007; Kintsch, 1988, 1998, \& 2006; OECD, 2003). However, one issue that must be addressed is the effect a participant's level of computer and Internet skill. The next section called 'Measurement Instruments' deals with these issues.

\subsection{RESEARCH DESIGN}

This study used a 2(text complexity) X 2(complex graphical elements) X 4(articles) fractional within-subjects design. The two levels for text complexity were high text complexity (HTC) ${ }^{\mathrm{iii}}$ and low text complexity (LTC) ${ }^{\mathrm{iii}}$. The two levels for complex graphical elements (CGE) ${ }^{\mathrm{ii}}$ were present and absent. The researcher crossed these factors in this way, so that each participant viewed each level but never saw more than one version of each original science article (Figure 2).

Stimuli. The researcher chose four original science articles from online science magazine Web sites or science publication Web sites. These articles were about the following topics: (1)Pluto losing its planetary status, (2)genetically engineering crops to improve photosynthesis, (3)the spread and origin of bird flu, and (4)scientists exploring anaerobic organisms to clean up chlorinated solvents in ground water (Mann, 1999; Sato, 2007; McCarty, 1997; Mackenzie, 2006). The variety of topics aided in seeing the overall 
impact on science and technology topics, and all articles had publication dates within the last ten years. A skilled magazine student from the journalism program at the University of Missouri-Columbia helped the researcher write each of these four articles into two versions of its original content, according to text complexity. The articles varied in three ways:

1. Whether the articles included more advance scientific terminology or commonplace words mixed with simpler scientific terminology,

2. Whether the simple scientific or technical explanations and definitions about the topic were present and if they were worded with scientific terminology or more commonplace words, and

3. Whether clear explanations of previous related research and findings were thoroughly present or just minimal reference was made to them.

Then the researcher next made each of these two versions into two further versions, according to the presence of CGE. They either had the original article's CGE or not. In the end, each article had four versions. One version of the text was HTC and included its CGE. Another version of the text was HTC and did not include its CGE. A third version of the text was LTC and included its CGE. A fourth version of the text was LTC and did not include its CGE. That makes 16 possible articles (Table 2) for a participant to get before he or she is randomly assigned to a random order of four of the different topics and versions. 


\begin{tabular}{|c|c|c|c|c|c|c|}
\hline & & & Article 1 & Article 2 & Article 3 & Article 4 \\
\hline \multirow{4}{*}{ 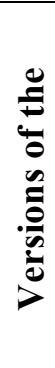 } & \multirow{4}{*}{ 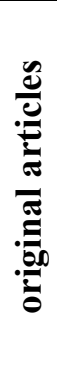 } & $\begin{array}{c}\text { HTC, } \\
\text { CGE not present }\end{array}$ & 1 & 2 & 2 & 4 \\
\hline & & $\begin{array}{c}\text { HTC, } \\
\text { CGE present }\end{array}$ & 5 & 6 & 7 & 8 \\
\hline & & $\begin{array}{c}\text { LTC, } \\
\text { CGE not present }\end{array}$ & 9 & 10 & 11 & 12 \\
\hline & & $\begin{array}{c}\text { LTC, } \\
\text { CGE present }\end{array}$ & 13 & 14 & 15 & 16 \\
\hline
\end{tabular}

Table 2: The articles examined in terms of the two levels of the two structural facets.

The experiment's design included two stimuli; three dependent, measurable, and within-subjects variables; and an independent, between-subjects variable: prior knowledge, besides gender, age, and education. The paper discusses these variables in further detail in their own sections in this chapter. Before getting into these variables, the format and layout need a clear explanation to see why they do not impede the variables.

The layout of the articles, as mentioned previously, depended on whether or not the CGE are present. The articles with CGE present were about the same length and shared a uniform layout of the text that included the placement of the CGE. The articles that did not include CGE were also the same length, and they shared a uniform layout. Thus, there were two general layouts used in this experiment. The same two layouts for all the articles eliminated the impact of varying layout structures, while still allowing the researcher to examine the impact of text complexity and the presence of CGE (Kendeou \& van den Broek, 2007; Kintsch, 1988, 1998, 2005; Lang, 2006; McNamara et al., 1996 Singer \& Kintsch, 2001).

Measurement Instruments. Now to measure the three within-subjects variables: recognition memory, problem-solving recall memory, and perception, and the betweensubject variable of prior knowledge, several measurement instruments were used. These 
included laboratory computers that displayed and timed the science articles and the questionnaires: pre-test questionnaire for each participant and a post-reading questionnaire for each article.

The articles used the same color scheme for text and background. Each had a scroll bar on the right for scrolling through the article; pop-up window capability on all CGE, if the article included them; a single 'Continue' button at the bottom on the right hand side of the screen to control movement; and a consistent layout used. However, since only half of the potential articles had CGE there were two types of layout designs. One layout design only included the text from the article. Thus, the title was on the top of the page, centered, in bold font and in 22-sized font. Underneath it was the author's name centered, in italics, and in 14-sized font. Meanwhile, the text of the story was aligned left, not indented, in paragraph form, and in 14-sized font.

The other layout design included the text and the CGE. The title, author's name, and the format of the text were the same as in the design with only text. However, after the first two paragraphs, the first CGE was on the right side with the third paragraph, which was aligned on the left side of the CGE. The caption was placed beneath its corresponding photo and was size 10 font. More than likely, CGE was not full size, but there was a pop-up window link on the smaller image, if the participant wished to click it. Another three paragraphs down was the location of the next CGE, but this time aligned left of that paragraph.

The two types of questionnaires, which Media Lab created, relied on self-reporting by the participants. They provided insight into the workings of mental processes of the participants' minds as well as background information about them. First, the pre-test 
questionnaire that was broken up into two parts: one before starting to read and the other after the completion of all the reading was presented to participants. The first part consisted of 12, timed questions about the area of science and technology. These 12 questions focused on the areas that the articles, which the participant read, covered. This set of questions aided in figuring out the PK level of each participant. While these questions were chosen by the researcher to match with the articles' topics, reference was made to previous tests and questionnaires used to learn about science literacy (SL), such as Miller's National Association of Science Writers (NASW) question set as well as Organisation for Economic Co-operation and Development (OECD)'s questionnaires for students (Miller, 2004; OECD, 2003). This provided a consistent way of wording and explaining (Miller, 2004). The second part of the pre-test questionnaire consisted of a set of seven, timed demographic questions. These were simply for organizing data as well as looking at other factors, such as education background and reading habits, which could influence PK.

Second, the timed post-reading questionnaire tested recognition memory, problemsolving ability under recall memory, and gave the participant a chance to comment on how he or she perceived the effectiveness of the science article in terms of comprehension. Four questions were recognition based, another four questions were problem-solving recall-based and the last four questions were about the effectiveness of the article: the reader's perception.

The recognition memory questions checked the participant's ability to recognize the difference between "old items" and "new items." Old items would be items that were in the article they read, while new items were not present in the article. The recognition 
questions had a 2-point scale: true or false (Shapiro, 1994; Norris et al., 2003; Gunter, 2000). The problem-solving recall memory ${ }^{\text {iv }}$ questions examined more in-depth memory retrieval and required participants to fill in missing information; thus, relying on their abilities to combine PK with new information they learned from the article. This leads to the "active processing" mentioned both by Kintsch $(1988,1998)$ and by McNamara et al. (1996). The questions about the effectiveness of the article were on a scale of 1 to 7 with 1 "I disagree completely with this statement" and 7 being "I agree completely with this statement." It examined interest, thoughts, and attitude towards the article, and perhaps, science and technology. All of these individual aspects made up or affected a reader's perception (Miller, 1998, 2004; Pardo \& Calvo, 2004; Norris et al., 2003; Tobias, 1994).

A single 'Continue' button at the very bottom, right hand side of the screen was used to move between articles' pages and their post-reading questions, and then on to the next article. The participants clicked on it with a mouse to move forward. This single button movement not only controlled movement between pages, but also it stopped people from going back to check answers and limited the impact of participants' poor Internet ability. In addition, the 'Continue' triggered the timer, which kept track of the length of time it took different readers to go through articles and questionnaires. There were two reasons for timing each part of the experiment: (1) to track the time for any correlation between the independent variable of prior knowledge and time and (2) to check on possible reasons for outliers in the results. For example, a person who finishes the reading in ten seconds and who has very random results on the corresponding questionnaire might need to be dropped because they did not give accurate or honest responses (Macedo-Rouet et al., 2003). 


\subsection{PARTICIPANTS AND RESEARCH PROCEDURES}

Participants. This study ran 136 undergraduate and graduate students from the University of Missouri-Columbia. There were three reasons for using a student population sample. First, the comprehension of technical topics both in the areas of education and new media have been done with college aged people previously (MacedoRouet et al., 2003; Salmerón et al., 2006; Kendeou \& van den Broek, 2007). Second, as long as a person is 18 or over, they fall into the category of people exposed to at least a high school level of science and technology education or experience. From there, the researcher can focus on the participant's level of familiarity with these technical areas and the level of education the participant has achieved. These levels were the deciding factors on the degree of impact that structural facets of an article have on his or her text comprehension. Third, among the basic requirements of college students is an ability to read. Thus, by choosing this sample population the study did not have to deal with possible illiterate individuals who will most likely not read any science articles (Norris et al., 2003).

Consent \& Pre-test questionnaire. Each participant was given an hour to run through the pre-reading questionnaire, his or her four random articles and their corresponding post-reading questionnaires. After the participant arrived, the researcher explained what was required of the participant and answered questions he or she may have. The researcher also explained the risks and benefits for the participant. For being a part of the study, each student received extra credit for their respective class in place of doing a paper of equal credit and time requirement. Then after the participant signed the consent form, each participant took the first part of the pre-reading test that was marked 
with an identification (ID) number on the computer. This ID number helped keep information matched up without having to risk individuals' privacy. The ID number carried through the rest of the experiment. The first part of the pre-reading questionnaire tested for the level of prior knowledge $(\mathrm{PK})^{\mathrm{i}}$.

Reading and post-reading questionnaires. Each participant received a random order of four articles without considering his or her PK level. The participant read one article at a time. Once they completed the reading of an article, they clicked the "Continue" button at the bottom right hand side of the screen, using the mouse, which took them to a 12 question post-reading questionnaire about what they just read. These questions included true and false questions, multiple-choice questions that required them to problem solve, and statements about the article that the participant decided how much he or she agreed with it. Then after they finished the post-reading questionnaire, they pushed another "Continue" button at the bottom right hand side of screen to take them to the next online science article. After the participant had gone through all of his or her four articles, they took the second part of the pre-test questionnaire. This part of the pretest questionnaire gathered demographic data necessary for the study. Once these questions were completed, the participant was debriefed. The researcher asked if he or she has any questions and thanked the participant for his or her help.

\subsection{INDEPENDENT VARIABLES}

Structural facets of an article. The two structural facets examined are text complexity and complex graphical elements (CGE) $)^{\mathrm{ii}}$. These independent variables were 
within-subject. The reason for it was that the participants received two articles of high text complexity (HTC) $)^{\mathrm{iii}}$ and two of low text complexity (LTC) $)^{\mathrm{iii}}$, and two contained the original article's CGE and two did not contain them.

The text manipulation depended upon the content complexity of article: whether the writer used casual and referential connections. Casual and referential connections refer back to the presence of inferential process. Casual inference allows for completely clear mental representations of ideas brought up in the text without having to use too much PK to fill in missing information. This also means that the text structure exists in a way that makes it more explicit, so that the establishment of more connections both casual and referential occurs without much PK or critical thinking. The more of connections, the easier it should be for a reader to understand the text (Linderholm et al., 2000). In several past studies done for science coverage in the areas of mass media (Norris et al., 2003) and education (McNamara et al., 1996; Lin et al., 2002; Kendeou \& van den Broek, 2007), complexity or coherence were found to affect the ability of a person to recall, recognize, and comprehend what he or she read. Thus, to test this impact, each article had two versions from both text complexity levels (Macedo-Rouet et al., 2003; Linderholm et al., 2000).

The study defined the text complexity levels in two ways. First, the articles varied in three ways:

1. Whether the articles included more advance scientific terminology or commonplace words mixed with simpler scientific terminology, 
2. Whether the simple scientific or technical explanations and definitions about the topic were present and if they were worded with scientific terminology or more commonplace words, and

3. Whether clear explanations of previous related research and findings were thoroughly present or just minimal reference was made to them.

Besides basing text complexity off the three previously mentioned guidelines, the articles were run through the Flesch-Kincaid Readability Test used by the Word ${ }^{\odot}$ document program to see what Flesch-Kincaid Grade Level they were considered. The article versions of high text complexity had a Grade Level of 13.3 or higher (Flesch Reading Ease is about 40.1 or below). Those article versions that of low text complexity had a Grade Level of 13.2 or lower (Flesch Reading Ease is about 40.2 or above). Table 3 shows the scores for the two different levels of text complexity for each of the four article topics. 


\begin{tabular}{|c|c|c|c|}
\hline Article Topic: & $\begin{array}{l}\text { Text Complexity } \\
\text { Level: }\end{array}$ & $\begin{array}{l}\text { Flesch-Kincaid } \\
\text { Grade Level: }\end{array}$ & $\begin{array}{l}\text { Flesch Reading } \\
\text { Ease Score (\%) }\end{array}$ \\
\hline Pluto losing its planetary status & High & 14.5 & 33.5 \\
\hline Pluto losing its planetary status & Low & 12.5 & 43.1 \\
\hline $\begin{array}{l}\text { Genetically engineering crops to } \\
\text { improve photosynthesis }\end{array}$ & High & 14.4 & 32.2 \\
\hline $\begin{array}{l}\text { Genetically engineering crops to } \\
\text { improve photosynthesis }\end{array}$ & Low & 12.4 & 42.5 \\
\hline The spread and origin of bird flu & High & 13.4 & 41.7 \\
\hline The spread and origin of bird flu & Low & 11.2 & 49.2 \\
\hline $\begin{array}{l}\text { Scientists exploring anaerobic } \\
\text { organisms to clean up chlorinated } \\
\text { solvents in ground water }\end{array}$ & High & 14.7 & 30.3 \\
\hline $\begin{array}{l}\text { Scientists exploring anaerobic } \\
\text { organisms to clean up chlorinated } \\
\text { solvents in ground water }\end{array}$ & Low & 13.1 & 36.2 \\
\hline
\end{tabular}

Table 3: The text complexity levels according to the Flesch-Kincaid Readability Test.

CGE varied by their presence or lack of it. Just like for text complexity, two versions of each original article contained CGE and two versions of each original article did not. Each participant received one version of each of the original four science articles. He or she had two articles with CGE and two without CGE. This procedure was to test three impacted or impactful events. First, it showed if the presence of CGE affected the three measuring variables for comprehension. Second, it proved if the presence of CGE or lack of it affected readers with different PK levels in a different way (Macedo-Rouet et al., 2003; Adaval et al., 2007). Third, it examined whether there was an interaction between CGE and text complexity in terms of influencing text comprehension (H2 and RQ3). 
Demographics. This study collected seven demographic variables: age, gender, highest level of education completed, current level in college, program of study currently, and about reading of science magazines, along with PK. Since all participants were from the same Midwestern university campus in the United States, the researcher believed it was important to control for differences among age groups, gender, the highest level of education completed, and the PK levels. 12 timed questions measured each readers PK level. The researcher based these questions off previously used questionnaires, which test people's knowledge on specific subjects in the science and technology areas (Miller, 2004; OECD, 2003).

\subsection{DEPENDENT VARIABLES}

Recognition Memory. Recognition is a version of memory. It tests how well the participant recognizes information they have encoded and indexed in short-term memory and long-term memory (LTM), while trying to avoid indicating information that is not from the article. A common way to test recognition is using true and false questions that check a person's recognition accuracy. Thus, it tests how well the participant recognizes information from the text he or she has previously read, i.e. getting a hit, while trying to avoid indicating information that was not from the text, i.e. getting a false alarm. The timed post-reading test had four true and false questions (Shapiro, 1994). According to Kitsch's Construction - Integration (C-I) model, recognition is an important facet of constructing memory $(1998,2005)$. If there is no impediment in understanding, then often recognition and simple recall is all that is required for an adult to show 
understanding (Kintsch, 1998). They were analyzed with repeated measures analysis of variance (ANOVA) for fractional within-subject and paired-sample T-test.

Problem-solving recall memory ${ }^{\mathrm{iv}}$. Recall memory relies upon indexing storage memory from LTM. Specifically, it requires cued recall memory, but since this variable was a researcher created one, it goes a step further and encourages "active processing" in people to assimilate - PK and the knowledge from the text combined into a usable form. This combination variable took the knowledge beyond just recognizing and started to apply it. To measure it, the timed post-reading questionnaires had four multiple-choice questions. They were analyzed with repeated measures ANOVA for fractional withinsubject and paired-sample T-test.

Perception of an online science article. Perception is primary part of the second version of comprehension as defined by Kintsch $(1998,2005)$. The way someone perceives a message affects how he or she comprehends. A reader's interest, attitude, and knowledge as well as aspects of the text affect perception (Falk et al., 2007; Evans \& Durant, 1995; Tobias, 1994). To measure perception, the timed post-reading tests consisted of four statements about the corresponding article that required participants to say how much they agree or disagree with each statement. They inquired about if the participant viewed the text as complex (Question 9), if the article was easy to understand (Question 10), if the article clearly or thoroughly explained the topic (Question 11), and if the topic of the article was interesting (Question 12). These questions were on a scale: 1 (I completely disagree with this statement.) to 7 (I completely agree with this statement). The scale asked for the participant to rate each statement according to his or her viewpoint. For example, "The text of this article is complex" and "This article was easy 
to understand." This study was particularly interested in comparing the perception found to the prior knowledge levels and the actual measured comprehension: recognition memory and problem-solving recall memory $(\mathrm{H} 3)$. The results from this section of the post-reading questionnaires were analyzed with bivariate correlation analysis. If any of the perception questions were found to have a significant Pearson Correlation Coefficient, then the researcher ran those significant ones through an equation that tested coefficients from the same sample population (Cohen \& Cohen, 1983). 


\section{CHAPTER 3: RESULTS}

This chapter covers the results found during the investigation of the study's data. A statistically analysis was done with the data for each of the three hypotheses mentioned below. In turn, the hypotheses' results had application toward answering the three research questions for this study, which Chapter 4 discusses in more detail.

\subsection{MANIPULATION CHECK}

Question 9 of the post-reading questionnaire inquired how the participant viewed the text complexity of the article (The text of the article is complex.). It helped to double check whether the defining of the level of text complexity of an article held true in the minds of the participants. The scaled results went through a repeated measures ANOVA analysis and paired-samples T-test. The first test showed that neither a reader's PK level or the presence of CGE correlates with perceived text complexity, but there is a significant $(\mathrm{p}=0.001)$ correlation between assumed text complexity, which is shown in Table 3, and perceived text complexity $\left(\mathrm{F}(1,108)=12.136\right.$, Partial $\left.\mathrm{Eta}^{2}=0.101\right)$. Table 4 shows the mean scores from this analysis.

\begin{tabular}{cc}
\hline \hline Text Complexity & Mean (Std. Dev.) \\
\hline \hline Low & $5.39(0.13)$ \\
High & $5.90(0.11)$ \\
\hline \hline
\end{tabular}

Table 4: The mean scores for Question 9 found by a repeated measures ANOVA for assumed text complexity correlating to perceived text complexity. 
The paired-samples T-test showed similar results to the previous analysis with a significant $(\mathrm{p}=0.001)$ correlation between assumed HTC and perceived HTC, but no correlation was found between readers' PK level and perceived text complexity. Specifically, looking at all participants $(\mathrm{N}=136)$ in terms of the presence of CGE through a paired-samples T-test, there was significant difference in mean scores between perceived text complexity and the presence of CGE $(t=2.374, \mathrm{df}=135, \mathrm{p}=0.019)$ and perceived text complexity and the lack of presence of CGE $(\mathrm{t}=2.198, \mathrm{df}=135, \mathrm{p}=$ 0.030) (RQ3). Table 5 shows the mean scores for both levels of CGE. Therefore, the study has shown that, according to the participants, the assumed text complexity of the articles' versions corresponds to what the participants' perceived the articles' text complexities.

\begin{tabular}{ccc}
\hline \hline CGE & Text Complexity & Mean (Std. Dev.) \\
\hline \hline \multirow{2}{*}{ Present } & Low & $5.48(0.02)$ \\
& High & $5.88(0.02)$ \\
\hline \hline \multirow{2}{*}{ Not Present } & Low & $5.48(0.02)$ \\
& High & $5.85(0.02)$ \\
\hline \hline
\end{tabular}

Table 5: The mean scores found for Question 9 in terms the CGE levels and text complexity levels, ignoring readers' PK levels.

\subsection{PRIOR KNOWLEDGE}

Since each hypothesis dealt with the varying impact due to prior knowledge $(\mathrm{PK})^{\mathrm{i}}$, the first analysis was to calculate the total PK score for each participant. All 136 participants had a PK score, which ranged from 0.25 to 1.00 . The mean of the scores was 
approximated to $0.61(\sigma=0.17)$. Thus, that was the dividing line between readers with high PK level and readers with low PK level. However, to get more accurate results and since the two extreme levels were of more interest to us, a more definite divide was needed to represent high and low PK levels. Thus, the closest score to 0.61 was removed, and the 26 people who got scores in the median $(\mathrm{PK}$ score $=0.58)$ were dropped from final analysis. In the end, there were 47 participants with a score in the low PK level (score $\leq 0.50)$ and 63 participants with a score in the high PK level (score $\geq 0.67)$ (Table 6). These were the participants used to answer the hypotheses and research questions, except when looking at hypothesis 3 .

\begin{tabular}{|c|c|c|c|}
\hline \multicolumn{2}{|c|}{ Low PK Level Scores } & \multicolumn{2}{|c|}{ High PK Level Scores } \\
\hline Score $(\%)$ & Frequency & Score $(\%)$ & Frequency \\
\hline 0 & 0 & 67 & 29 \\
\hline 25 & 3 & 75 & 16 \\
\hline 33 & 9 & 83 & 5 \\
\hline 42 & 10 & 92 & 12 \\
\hline 50 & 25 & 100 & 1 \\
\hline Total \#: & 47 & Total \#: & 63 \\
\hline
\end{tabular}

Table 6: These are the frequencies of the participants' scores used in the final analysis this study's results.

While many factors influence readers PK levels, the study looked at a few particular ones. Education has an obvious effect on PK level, since everyone goes through at least the basic level of school and in college focuses on a particular area of study (Table 7 and Table 8). However, the media is another source for many people after school or in addition to school (Table 9). Thus, both were examined to see if there was any sort of 
correlation between them and readers' PK levels. However, only the number of magazines read per month held any clear sign of influence on readers' PK levels, but even those results were not absolute.

\begin{tabular}{cc||cc}
\hline \hline \multicolumn{2}{c||}{$\begin{array}{c}\text { Low PK Level Scores } \\
\text { Education Level }\end{array}$} & Frequency & High PK Level Scores \\
\hline \hline Freshmen & 1 & Freshmen & 3 \\
Sophomore & 10 & Sophomore & 15 \\
Junior & 17 & Junior & 20 \\
Senior & 10 & Senior & 8 \\
Masters & 5 & Masters & 15 \\
PhD & 4 & PhD & 2 \\
\hline \hline Total \#: & $\mathbf{4 7}$ & Total \#: & $\mathbf{6 3}$ \\
\hline \hline
\end{tabular}

Table 7: These frequencies refer to the current level of education identified by the participants, and they are broken up according to the two PK levels.

\begin{tabular}{|c|c|c|c|}
\hline \multicolumn{2}{|c|}{ Low PK Level Scores } & \multicolumn{2}{|c|}{ High PK Level Scores } \\
\hline Program & Frequency & Program & Frequency \\
\hline Journalism & 41 & Journalism & 58 \\
\hline Communication & 2 & Communication & 1 \\
\hline Business & 1 & Business & 2 \\
\hline Medicine & 2 & Medicine & 0 \\
\hline Law & 0 & Law & 1 \\
\hline Science & 1 & Science & 1 \\
\hline Total \#: & 47 & Total \#: & 63 \\
\hline
\end{tabular}

Table 8: These frequencies refer to the participants' programs of study, which they specified from a list, and they are broken up according to the two PK levels. 


\begin{tabular}{|c|c|c|c|}
\hline \multicolumn{2}{|c|}{ Low PK Level Scores } & \multicolumn{2}{|c|}{ High PK Level Scores } \\
\hline $\begin{array}{l}\text { Magazines per } \\
\text { month }\end{array}$ & Frequency & $\begin{array}{l}\text { Magazines per } \\
\text { month }\end{array}$ & Frequency \\
\hline 0 & 39 & 0 & 50 \\
\hline 1 to 2 & 8 & 1 to 2 & 10 \\
\hline 3 to 5 & 0 & 3 to 5 & 0 \\
\hline 6 to 8 & 0 & 6 to 8 & 3 \\
\hline 9 or more & 0 & 9 or more & 0 \\
\hline Total \#: & 47 & Total \#: & 63 \\
\hline
\end{tabular}

Table 9: These frequencies refer to how many times per month the participants specified they read science magazines, and they are broken up according to the two PK levels.

\subsection{TEXT COMPLEXITY}

Hypothesis 1 dealt with the structural facet of text complexity only. There was an expectation in this hypothesis that the influence of text complexity would vary due to readers' PK levels. According to this hypothesis, there should be a significant interaction between PK and text complexity, such that readers with low PK would have high text comprehension with low text complexity (LTC) iii $^{\text {ii }}$ and readers with high PK level would have high text comprehension with high text complexity (HTC) ${ }^{\mathrm{iii}}$. Separate repeated measure ANOVA analyses and paired-samples T-tests on recognition memory questions and problem-solving recall memory questions checked to see how the text complexity levels influence these parts of text comprehension. After the analysis, the results partially supported this hypothesis. 


\subsubsection{RECOGNITION MEMORY}

The first analysis done was a repeated measures ANOVA that examined any interactions. Text complexity for the recognition memory questions showed that there was significant $(\mathrm{p}=0.05)$ interaction $\left(\mathrm{F}(1,108)=3.808\right.$, Partial $\left.\mathrm{Eta}^{2}=0.034\right)$ between text complexity and a reader's PK level (RQ2). Figure 5 show the mean scores found for both levels of text complexity at both PK levels under this analysis.

\section{Mean Scores for Recognition Memory Questions}

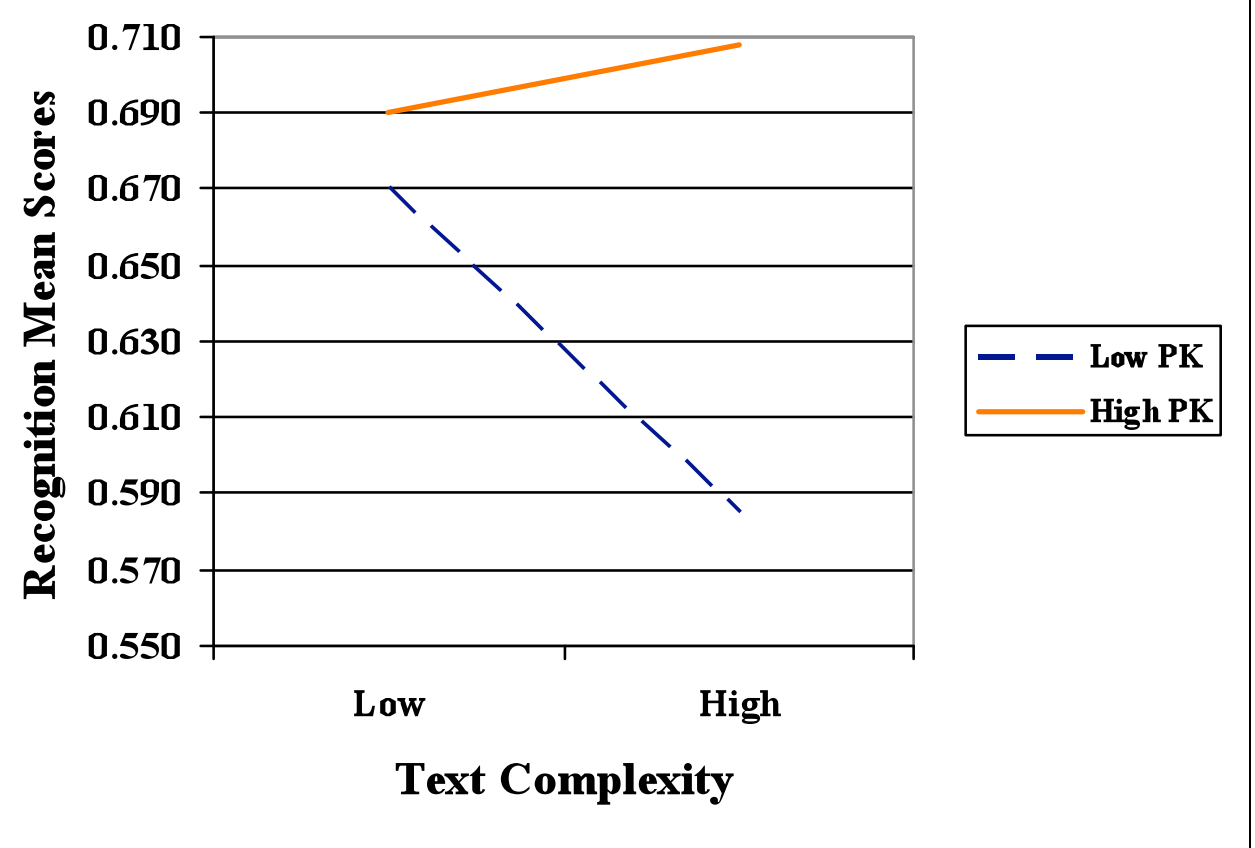

Figure 5: This graph illustrates the recognition memory questions mean scores in terms of how each level of text complexity influences it, and how that influence varies with the readers' PK levels.

Once an overall analysis showed a significant interaction, the next step was to do a closer examination looking specifically at the significance of the interaction at each PK level. Paired-Samples T-test examined the significant difference between mean scores at 
each PK level for recognition, ignoring whether or not complex graphical elements $(\mathrm{CGE})^{\mathrm{ii}}$ were present in the article. The study found that only readers with low PK level $(\mathrm{N}=47)$ were significantly $(\mathrm{p}=0.03)$ affected by text complexity $(\mathrm{t}=-2.237, \mathrm{df}=46)$. Readers with a high PK level $(\mathrm{N}=63)$ saw little difference in mean scores between reading at HTC and LTC. Table 10 shows both PK levels mean scores at both levels of text complexity.

\begin{tabular}{ccc}
\hline $\begin{array}{c}\text { PK } \\
\text { Level }\end{array}$ & $\begin{array}{c}\text { Text Complexity } \\
\text { Level }\end{array}$ & $\begin{array}{c}\text { Mean } \\
\text { (Std. Dev.) }\end{array}$ \\
\hline \hline \multirow{2}{*}{ Low } & Low & $0.670(0.16)$ \\
& High & $0.585(0.18)$ \\
\hline \hline \multirow{2}{*}{ High } & Low & $0.691(0.19)$ \\
& High & $0.708(0.19)$ \\
\hline \hline
\end{tabular}

Table 10: The mean scores found by a paired-samples T-test for the influence of the two PK levels and the two text complexity levels on recognition memory questions.

Therefore, in terms of recognition memory, Hypothesis 1 holds partially true, at least in terms of readers with low PK level. The readers with high PK level did show the results heading in the expected direction, but there proved to be no significant difference between the mean scores of the two levels of text complexity (RQ2). However, this does not give the complete answer to this hypothesis, because questions concerning problemsolving recall memory also need analysis. 


\subsubsection{PROBLEM-SOLVING RECALL MEMORY}

The problem-solving recall memory questions went through the same examination as the recognition memory questions. The results showed no significant $(p=0.11)$ interaction between text complexity and a reader's PK level, but the results did go in the expected direction (RQ2). Table 11 and Figure 6 demonstrate how the mean scores for problem-solving recall memory vary between levels in PK and text complexity.

\begin{tabular}{ccc}
\hline \hline PK level & Text Complexity Level & Mean (Std. Dev.) \\
\hline \hline Low & Low & $0.574(0.03)$ \\
& High & $0.495(0.03)$ \\
\hline \hline \multirow{2}{*}{ High } & Low & $0.637(0.03)$ \\
& High & $0.655(0.03)$ \\
\hline \hline
\end{tabular}

Table 11: The mean scores found by a repeated measures ANOVA for the interaction between the two text complexity levels and the two PK levels for the problem-solving memory questions. 


\section{Mean Scores for Problem-Solving Recall Memory Questions}

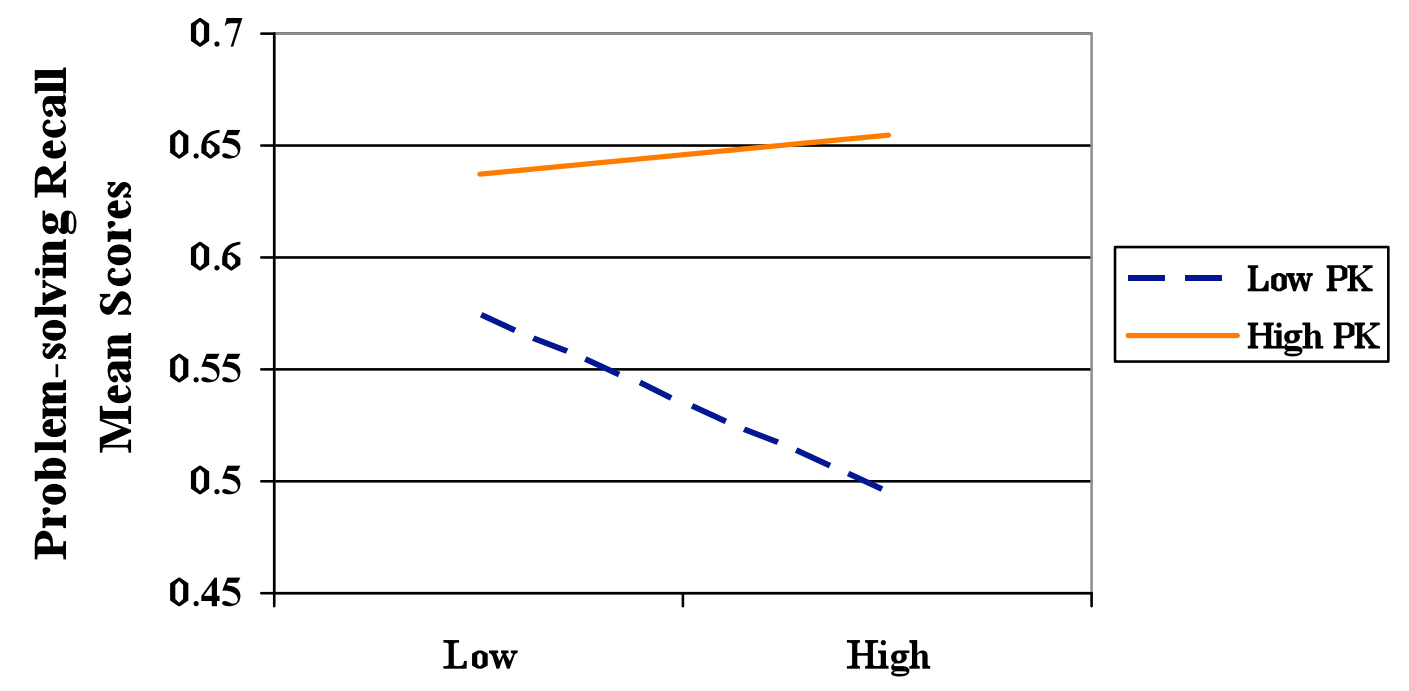

Text Complexity

Figure 6: This graph illustrates the problem-solving recall memory questions mean scores in terms of how each level of text complexity influences it, and how that influence varies with the readers' PK levels.

When paired-samples T-tests were run for both levels of PK, there still was no significant $(\mathrm{p}=0.093)$ effect, if you ignore whether they have CGE or not. However, if you only look solely at articles without CGE, there is significant $(p=0.016)$ effect $(t=-$ 2.503, $\mathrm{df}=46)$ for readers with low PK level, but there is no significant $(\mathrm{p}=0.650)$ effect for readers with high PK level. Thus, just like the results for recognition memory, hypothesis 1 holds partially true for problem-solving recall memory. Overall, the first part of the hypothesis, dealing with reader with low PK and reading LTC articles, is true (RQ3). Table 12 shows the mean scores for each level of text complexity when CGE are not present according to the PK level. 


\begin{tabular}{ccc}
\hline \hline $\begin{array}{c}\text { PK } \\
\text { Level }\end{array}$ & $\begin{array}{c}\text { Text Complexity } \\
\text { Level }\end{array}$ & $\begin{array}{c}\text { Mean } \\
\text { (Std. Dev.) }\end{array}$ \\
\hline \hline Low & Low & $0.601(0.28)$ \\
& High & $0.463(0.28)$ \\
\hline \hline High & Low & $0.619(0.24)$ \\
& High & $0.639(0.30)$ \\
\hline \hline
\end{tabular}

Table 12: The mean scores found by a paired-samples T-test for the influence of the two PK levels and the two text complexity levels on problem-solving recall memory questions.

\subsection{THE PRESENCE OF COMPLEX GRAPHICAL ELEMENTS}

Hypothesis 2 dealt directly with how CGE influence a reader's text comprehension. It looked at the influence in terms of the PK level of the readers (RQ1). Specifically, there is significant interaction between prior knowledge and the presence of CGE, such that readers with low PK level will have higher text comprehension when CGE are present, but readers with high PK levels will see no significant difference in their text comprehension whether or not CGE are present. After analysis, this hypothesis did not hold true for either PK level.

\subsubsection{RECOGNITION MEMORY}

The analysis first consisted of an examination on the influence of CGE on the recognition memory questions' data. A repeated measures ANOVA, looking at both levels of $\mathrm{PK}$, proved that there was no significant $(\mathrm{p}=0.78)$ interaction $(\mathrm{F}<1)$ between CGE and a reader's PK level. Table 13 shows the mean values from this analysis for each text complexity level under each PK level. 


\begin{tabular}{ccc}
\hline \hline $\begin{array}{c}\text { PK } \\
\text { Level }\end{array}$ & CGE & $\begin{array}{c}\text { Mean } \\
\text { (Std. Dev.) }\end{array}$ \\
\hline \hline Low & Not Present & $0.620(0.03)$ \\
& Present & $0.636(0.03)$ \\
\hline \hline High & Not Present & $0.698(0.02)$ \\
& Present & $0.700(0.02)$ \\
\hline
\end{tabular}

Table 13: The mean scores found by a repeated measures ANOVA for the interaction between the two CGE levels and the two PK levels for the recognition memory questions.

When recognition memory questions went through a paired-samples T-test for each PK level, looking only at articles with CGE, both PK levels: low $(p=0.69)$ and high $(p=$ 0.95), were not found to have a significant difference in mean scores (Table 14), even though the results of low PK readers were heading in the expected direction. In addition, the difference between the mean scores for high PK readers is smaller than for low PK readers. Thus, in terms of recognition memory, the hypothesis is not holding true. However, before making a final judgment, the problem-solving recall memory questions need analysis.

\begin{tabular}{ccc}
\hline $\begin{array}{c}\text { PK } \\
\text { Level }\end{array}$ & CGE & $\begin{array}{c}\text { Mean } \\
\text { (Std. Dev.) }\end{array}$ \\
\hline \hline Low & Not Present & $0.620(0.18)$ \\
Present & $0.636(0.17)$ \\
\hline \hline High & Not Present & $0.698(0.17)$ \\
& Present & $0.700(0.18)$ \\
\hline \hline
\end{tabular}

Table 14: The mean scores found by a paired-samples T-test for the influence of the two CGE levels and the two PK levels on recognition memory questions. 


\subsubsection{PROBLEM-SOLVING RECALL MEMORY}

As with hypothesis 1 , these problem-solving recall questions needed analysis to gain a full understanding of hypothesis 2 . These questions went through a repeated measures ANOVA as well as paired-samples T-tests. The results are the same as with the recognition memory questions. There is no significant $(\mathrm{p}=0.514)$ interaction $(\mathrm{F}<1)$ between CGE and PK levels (Table 15). However, the results for low PK readers showed higher mean scores when CGE are present.

\begin{tabular}{ccc}
\hline $\begin{array}{c}\text { PK } \\
\text { Level }\end{array}$ & CGE & $\begin{array}{c}\text { Mean } \\
\text { (Std. Dev.) }\end{array}$ \\
\hline \hline Low & Not Present & $0.532(0.03)$ \\
& Present & $0.537(0.02)$ \\
\hline \hline High & Not Present & $0.629(0.03)$ \\
& Present & $0.663(0.02)$ \\
\hline \hline
\end{tabular}

Table 15: The mean scores found by a repeated measures ANOVA for the interaction between the two CGE levels and the two PK levels for the problem-solving recall memory questions.

The paired-samples T-tests show the same result (Table 16) with no significant $(\mathrm{p}=$ 0.87) difference between mean scores for readers with low PK level and no significant ( $p$ $=0.25)$ difference between mean scores for readers with high PK level. Thus, according to both recognition memory and problem-solving recall memory, this hypothesis does not hold true. 


\begin{tabular}{ccc}
\hline \hline $\begin{array}{c}\text { PK } \\
\text { Level }\end{array}$ & CGE & $\begin{array}{c}\text { Mean } \\
\text { (Std. Dev.) }\end{array}$ \\
\hline \hline Low & Not Present & $0.532(0.21)$ \\
& Present & $0.537(0.15)$ \\
\hline \hline & Not Present & $0.629(0.21)$ \\
High & Present & $0.663(0.16)$ \\
\hline \hline $\begin{array}{l}\text { Table 16: The mean scores found by a paired-samples T-test } \\
\text { for the influence of the two CGE levels and the two PK levels } \\
\text { on problem-solving recall memory questions. }\end{array}$
\end{tabular}

\subsubsection{TEXT COMPLEXITY AND COMPLEX GRAPHICAL ELEMENTS}

Before examination of the final hypothesis, the researcher next explored any interaction between the structural facets (RQ3). A repeated measures ANOVA of the actual text comprehension variables: recognition memory and problem-solving recall memory, showed that there was no significant $(p>0.05)$ interaction when looking between the two structural facets (Table 17) or between the structural facets and readers' PK levels (Table 18). These mean scores show that there is some sort of interaction going on between the structural facets. This interaction varies with the readers' PK level when looking solely at the actual text comprehension (memory), but is still not significant. However, there was a significant $(\mathrm{p}=0.03)$ interaction $\left(\mathrm{F}(1,108)=4.848\right.$, Partial $_{\mathrm{Eta}}{ }^{2}=$ 0.043 ) between text complexity and the presence of CGE for the perception question on the article's ability to explain the topic (Question 11), as shown in Table 19. 


\begin{tabular}{cccc}
\hline $\begin{array}{c}\text { Text } \\
\text { Complexity }\end{array}$ & $\begin{array}{c}\text { Actual Text } \\
\text { Comprehension }\end{array}$ & CGE & $\begin{array}{c}\text { Mean } \\
\text { (Std. Dev.) }\end{array}$ \\
\hline \hline \multirow{2}{*}{ Low } & Recognition & Not Present & $0.681(0.03)$ \\
& Present & $0.680(0.02)$ \\
\hline \hline \multirow{2}{*}{ High } & Recognition & Not Present & $0.637(0.02)$ \\
& Problem-solving & Present & $0.656(0.02)$ \\
\hline \multirow{2}{*}{ Low } & Recall & Present & $0.610(0.03)$ \\
& Problem-solving & Not Present & $0.601(0.03)$ \\
\hline \multirow{2}{*}{ High } & Recall & Present & $0.551(0.03)$ \\
& Resent & $0.559(0.03)$ \\
\hline \hline
\end{tabular}

Table 17: The mean scores found by a repeated measures ANOVA for the interaction between the two text complexity levels and the two CGE levels.

\begin{tabular}{|c|c|c|c|c|}
\hline $\begin{array}{c}\text { Actual Text } \\
\text { Comprehension } \\
\end{array}$ & $\begin{array}{c}\text { PK } \\
\text { Level } \\
\end{array}$ & $\begin{array}{c}\text { Text } \\
\text { Complexity } \\
\end{array}$ & CGE & $\begin{array}{c}\text { Mean } \\
\text { (Std. Dev.) } \\
\end{array}$ \\
\hline \multirow{8}{*}{ Recognition } & \multirow{4}{*}{ Low } & \multirow{2}{*}{ Low } & Not Present & $0.660(0.04)$ \\
\hline & & & Present & $0.681(0.04)$ \\
\hline & & \multirow{2}{*}{ High } & Not Present & $0.580(0.04)$ \\
\hline & & & Present & $0.590(0.04)$ \\
\hline & \multirow{4}{*}{ High } & \multirow{2}{*}{ Low } & Not Present & $0.702(0.03)$ \\
\hline & & & Present & $0.679(0.03)$ \\
\hline & & \multirow{2}{*}{ High } & Not Present & $0.694(0.03)$ \\
\hline & & & Present & $0.722(0.03)$ \\
\hline \multirow{8}{*}{$\begin{array}{c}\text { Problem-solving } \\
\text { Recall }\end{array}$} & \multirow{4}{*}{ Low } & \multirow{2}{*}{ Low } & Not Present & $0.601(0.04)$ \\
\hline & & & Present & $0.548(0.04)$ \\
\hline & & \multirow{2}{*}{ High } & Not Present & $0.463(0.04)$ \\
\hline & & & Present & $0.527(0,04)$ \\
\hline & \multirow{4}{*}{ High } & \multirow{2}{*}{ Low } & Not Present & $0.619(0.04)$ \\
\hline & & & Present & $0.655(0.03)$ \\
\hline & & \multirow{2}{*}{ High } & Not Present & $0.639(0.04)$ \\
\hline & & & Present & $0.671(0.03)$ \\
\hline
\end{tabular}

Table 18: The mean scores found by a repeated measures ANOVA for the interaction between the two text complexity levels, the two CGE levels, and the two PK levels.

\begin{tabular}{ccc}
\hline \hline CGE & Text Complexity & Mean (Std. Dev.) \\
\hline \hline \multirow{2}{*}{ Not Present } & Low & $4.89(0.15)$ \\
Present & High & $4.72(0.15)$ \\
& Low & $5.07(0.14)$ \\
& High & $4.40(0.16)$ \\
\hline \hline
\end{tabular}

Table 19: The mean scores found for Question 11 in terms of the two text complexity levels and the two CGE levels, ignoring readers' PK levels. 


\subsection{THE PERCEPTION OF AN ONLINE SCIENCE ARTICLE}

Hypothesis 3 deals with the perception side of text comprehension. It looks at how perception correlates with PK and actual text comprehension (memory). According to the hypothesis, there will be a stronger correlation between a reader's perception of a science article and prior knowledge than any correlation between the reader's perception of a science article and actual text comprehension (memory). The three scale statements, which included one question (Question 11 from the post-reading questionnaire) about the article's ability to explain the topic, had two other consistent questions in each topic's post-reading questionnaire about the following:

- This article was easy to understand. (Question 10)

- The topic of this article was interesting. (Question 12)

Thus, a bivariate correlation analysis was done for each of the three perception questions that related to it in terms of PK level and actual text comprehension. Then coefficients for the two parts of the hypothesis: perception and PK versus perception and actual text comprehension, underwent coefficient comparison analyses to see if they were significant. The results showed that the hypothesis did not have support, and in fact, the correlation was stronger between perception and actual text comprehension.

\subsubsection{DOES PERCEPTION CORRELATE WITH PRIOR KNOWLEDGE?}

All three questions were analyzed using bivariate correlation analyses to see how they correlated with the PK scores. All 136 participants' scores were included and it was found that only for the question concerning interest in the article topic (Question 12) had a significant $(\mathrm{p}=0.02)$ correlation with PK scores $($ Pearson Correlation Coefficient $=$ 
0.199). In the questions that concerned understanding the article and the ability of the article to explain the topic, the analysis showed that there was no significant $(\mathrm{p}>0.05)$ correlation between perception and PK. However, as mentioned in the previous section, there was a significant interaction between the two structure facets (Table 19). However, before confirming whether this hypothesis holds true, the researcher needed to look at any correlation between perception and actual text comprehension.

\subsubsection{DOES PERCEPTION CORRELATE WITH ACTUAL TEXT}

\section{COMPREHENSION?}

All three questions ran through analysis again, and this time, since the correlation was between perception and actual text comprehension (memory), it was broken up according to recognition memory questions and problem-solving recall memory questions. Through this analysis, the study found that the question concerning interest in the article (Question 12 showed a significant correlation between perception and actual text comprehension (memory) for both recognition memory $(\mathrm{p}<0.05$, Pearson coefficient $=0.330)$ and problem-solving recall memory $(\mathrm{p}=0.023$, Pearson Correlation Coefficient $=0.195)$. When looking between the Pearson Correlation Coefficients (Table 20) the one for recognition memory and perception is the largest. This result suggests that that the correlation between actual text comprehension and perception is stronger than between PK and perception.

To be statistically accurate, the researcher performed coefficient comparison equation for the situation when the coefficients come from the same sample population (Cohen \& Cohen, 1983). This equation required a coefficient also between PK and recognition 
memory $(\mathrm{p}=0.001$, Pearson Correlation Coefficient $=0.293)$, and between PK and problem-solving recall memory $(\mathrm{p}<0.05$, Pearson Correlation Coefficient $=0.368)$. The results from the analyses showed no significance $(\mathrm{p}=0.16)$ for recognition memory, but problem-solving recall memory had a significant $(\mathrm{p}=0.05)$ difference. Thus, the overall results do not support hypothesis 3 .

\begin{tabular}{ccc}
\hline Bivariate Correlations & Significance & $\begin{array}{c}\text { Pearson Correlation } \\
\text { Coefficient }\end{array}$ \\
\hline \hline PK and Perception & 0.02 & 0.199 \\
Recognition Memory and Perception & 0.00 & 0.330 \\
Problem-solving Recall Memory and Perception & 0.02 & 0.195 \\
Recognition Memory and PK & 0.01 & 0.239 \\
Problem-solving Recall Memory and PK & 0.00 & 0.368 \\
\hline \hline
\end{tabular}

Table 20: The bivariate correlation results concerning Question 12 of the post-reading questionnaire. 


\section{CHAPTER 4: DISCUSSION \& CONCLUSIONS}

This chapter discusses the conclusions drawn from the results as well as the study's limitations and suggestions for future research. The results showed some significance in the mean effects and interactions or correlations between the variables: independent and dependent. The next step is discussing the theoretical and practical implications of these results, and then concluding whether they influence and how they influence the area of research on the public understanding of science as well as for the science media.

\subsection{SUMMARY OF RESULTS}

The researcher analyzed all three hypotheses using repeated measures ANOVA and paired-samples T-tests. Each hypothesis had its variables analyzed for interactions or correlations. When there was something significant or results appeared to be going in the expected direction, the researcher did a closer examination on the variables for that hypothesis. Then the difference between the mean scores of specific structural facets: text complexity and complex graphical elements (CGE) $)^{\mathrm{ii}}$, came under scrutiny to see exactly how, according to the prior knowledge (PK) level interaction or PK level main effect, it reacted.

The results showed that only text complexity interacts with readers' PK levels with any significant support from the study's data (H1). There was a significant interaction occurring between text complexity and readers' PK levels for the recognition memory questions $\left(\mathrm{p}=0.05, \mathrm{~F}(1,108)=3.808\right.$, Partial $\left.\mathrm{Eta}^{2}=0.034\right)$. The problem-solving recall memory ${ }^{\text {iv }}$ questions' results were not significant, but did go in the expected direction 
when not considering CGE. Table 10 and Table 11 show the mean scores found, and Figure 5 and Figure 6 illustrate the mean scores on both text complexity levels according to the PK level. In the case of articles without CGE, there is a significant $(p=0.016)$ effect $(t=-2.503)$ for readers with low PK level for problem-solving recall memory questions (Table 12).

For CGE, there was no interaction between it and a reader's PK level (H3). However, concerning Question 11, which is about an article's ability to explain the topic, there is a significant $(\mathrm{p}=0.03)$ interaction $\left(\mathrm{F}(1,108)=4.848\right.$, Partial $\left.\mathrm{Eta}^{2}=0.043\right)$ occurring between CGE and text complexity (Table 19 and Figure 7). This interaction, though not significant, for the actual text comprehension (memory) questions did seem to be going in the expected direction (H3). This result suggests a possible combined influence on text comprehension (RQ3). 


\section{Mean Scores for Text Complexity on both CGE levels}

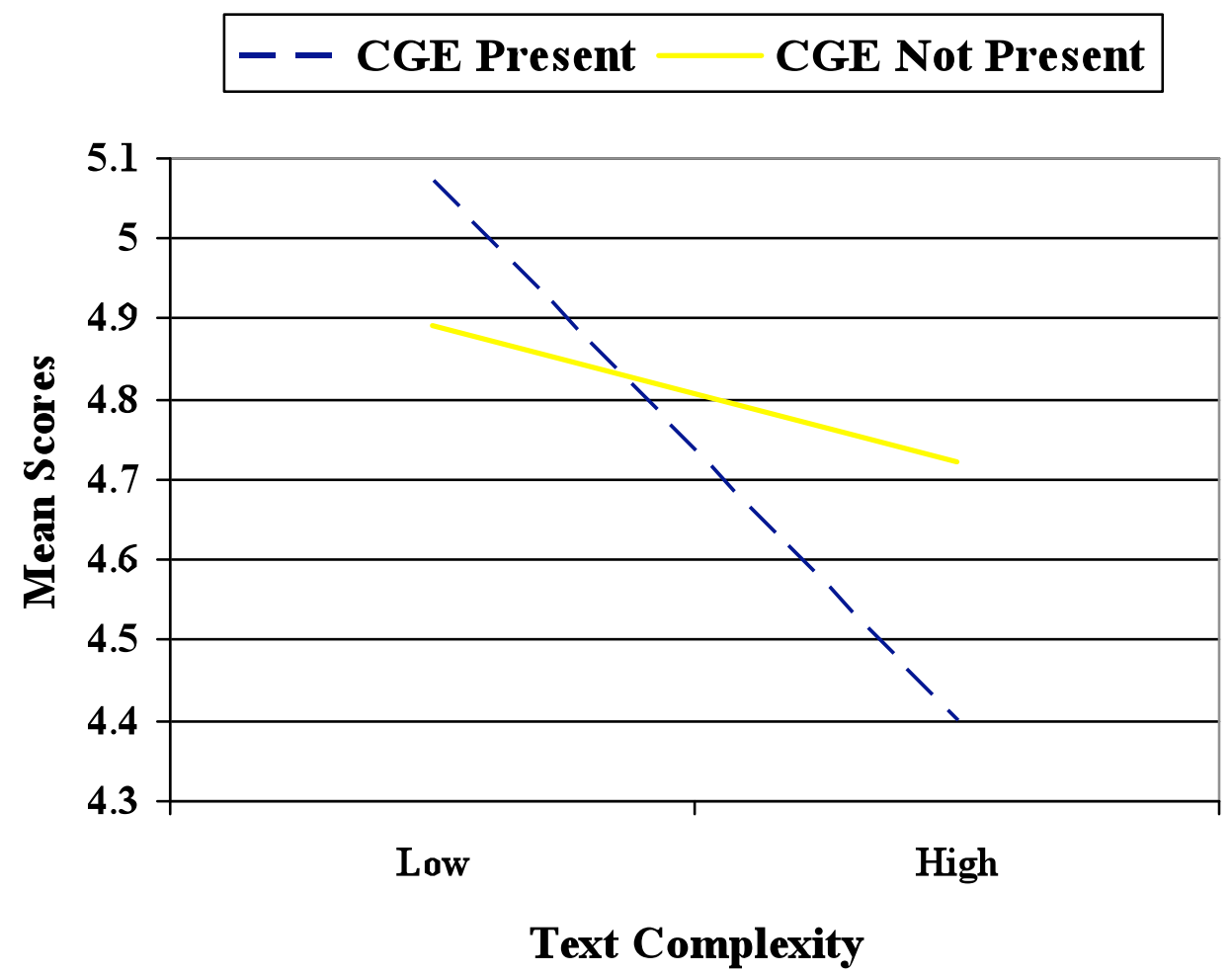

Figure 7: The graph illustrates the text complexity mean scores for Question 11 in terms of how each level of CGE influences the results.

As for perception, it significantly correlated with readers' PK levels and actual text comprehension for the perception question dealing with interest in the article's topic (Question 12) (H3). Actual text comprehension is recognition memory and problemsolving recall memory (Table 20). It also showed that readers' perceived text complexity of an article coincided with assumed text complexity as well as CGE affecting readers' perceived text complexity (Table 4 and Table 5). 


\subsection{DISCUSSING THE RESULTS}

Now that the hypotheses underwent analysis, showing whether the data supported them, there is a much better idea about the influence of these two structural facets of the science articles on a reader's text comprehension (RQ1). Current theories and research suggest that both the complexity of the text and the presence of visuals - CGE in the case of this study - should have an influence on a reader's text comprehension. The influence on text comprehension should not be the same for every person. Specifics drawn from previous research suggest that a reader's ability to cognitively process text could vary upon many factors about the text properties, format properties, page properties, and reader characteristics. In fact, the amount of background knowledge and experience on the topic should significantly affect these structural facets' influence. As mentioned previously, this study looked at the readers' PK level and two structural facets of the article for analysis. These three variables established the research questions for this study

\subsubsection{PRIOR KNOWLEDGE}

Earlier research suggested that this independent variable is reflective of an individual's prior experience, exposure (Table 9), education (Table 7 and Table 8), and knowledge concerning the area of the topic of the text or article (Table 6). Of course, the frequencies concerning education and exposure from science magazines were not reflective, but there was no strong endeavor to examine these influences on PK level. Nonetheless, previous research suggests PK level should have an effect on how well a reader reads and understands the article and its topic as well as how well he or she takes in information from it. From the PK level scores measured and the scores from the post- 
reading questionnaires, there certainly does seem to be an effect from a reader's PK. Even though the interaction between PK and the structural facets was not always significant, there was a difference in the mean scores in the expected direction. Therefore, the theory about an individual's knowledge and experience on the topic of the text or article, and how they influence text comprehension and a reader's ability to retrieve information is true to a point. Looking closely at what happened with each structural facet as well as the perception side of text comprehension explains why.

\subsubsection{TEXT COMPLEXITY}

Just looking solely at text complexity's effect on text comprehension there was an influence on readers' cognitive processing of information from a text, and the effect varied with readers' PK levels (H1 and RQ2). Text complexity draws upon the word choice and phrasing in the writing. Theoretically, the more complex the words being used or the less coherently organized the text, the more knowledge and familiarity is needed by the readers. Their short-term memory (STM), which recognition memory questions tested, showed that readers with low PK were better able to recognize information from a low text complexity (LTC) $)^{\mathrm{iii}}$ article than from a high text complexity (HTC) ${ }^{\mathrm{iii}}$ article. Similar results were found with their long-term memory (LTM), which problem-solving recall memory questions challenged. However, it was obvious that STM was much easier for low PK reader to draw from, since it did not require digging as much into their PK. The problem-solving recall memory questions required more schemata on the topic to answer them. 
In contrast, there was no significant interaction between text complexity and PK for readers with high PK level, but the scores did go in the expected direction. When looking just at readers with high PK level, in terms of their STM and LTM, it is obvious their recognition memory mean scores were better than the recognition memory of low PK readers. The researcher observed that the data showed, even though not significant, the readers with high PK level did better on both levels of text complexity. For problemsolving recall memory, this also holds true to previous theories, because these types of questions rely on an individual's PK. Thus, readers with high PK level tended to score higher on problem-solving memory questions than readers with low PK levels (Table 15 and Table 16). These results suggest to the researcher that there could be something there. Further research is required on this group of readers.

Therefore, these results leave the conclusion that text complexity can be significantly influential to a reader's text comprehension. Even looking at the scaled results from the perception questions, there was a significant effect by text complexity on how readers perceived different aspects of the article. This result suggests that text complexity in terms of the casual and referential connections needs consideration in a science or technology article. Obviously, the study cannot say anything definite for LTC article, but HTC articles can have conclusions drawn about it.

The researcher would suggest science journalists and the science media must consider their word choice and phrasing, because it does have an effect. Readers with low PK levels struggle with the HTC science article. As for the readers with high PK levels, there is nothing definite about how they react with the different levels of text complexity, but the mean scores did suggest they did better with higher text complexity. Thus, as prior 
research suggests, a science journalist can reach a wider audience by not writing too simply, bogging down the text with definitions and detailed explanations, but at the same time, he or she must strive not to chalk the article full of advanced terminology and references without supplying some clearly written and clarified explanations and reasons. These results are still on the vague side and would need further research on more broken up levels of text complexity.

\subsubsection{COMPLEX GRAPHICAL ELEMENTS}

As for the CGE, previous research in the areas of education and newspapers suggests the presence of visuals should have an impact, but only on readers with low PK level. Specifically, these type of readers should find their text comprehension are better when a visual is present than when it is not present. The additional assistance should be beneficial to them in gaining an understanding of more complex texts. Readers with high PK level should see no difference in their text comprehension whether or not CGE is present. Unfortunately, this study found no significant results for CGE in terms of readers' PK levels $(\mathrm{H} 2)$. Thus, nothing definite can be said, but from the mean scores concerning solely whether CGE were present or not, the results do seem to be going in the expected direction in terms of recognition memory (Table 13 and Table 14). This result suggests hypothesis 2 might hold true. It would mean that CGE or visuals in an article could influence text comprehension of low PK readers and have very little influence on the text comprehension of high PK readers.

Concluding from these findings, CGE does not have as much of an influence on readers' text comprehension as text complexity. The study does not suggest this is the 
case for sure or all the time. Since the results never found significance in terms of the PK levels of readers, there might still be some influence, but it might depend more upon the type of visual being utilized, the presentation of the visual, or something more specific about the topic or visual. Perhaps CGE just happened to be a type not as useful or not liked by these participants, i.e. readers. It is also possible that there are other reasons, which are examined in the section on "Limitations of the Research \& Future Research," for this lack of significance in the presence of CGE in this study.

\subsubsection{TEXT COMPREHENSION}

This variable was at the center of this entire study. Each reader cognitively processes the message coming out of a text or an article. The structural facets influence this process, which draws upon a reader's schemata. By looking at the results due to these structural facets but in terms of text comprehension, this perspective presented a different variety of implications and conclusions.

First, it allowed for an examination of the two structural facets and their combined influence on text comprehension. The researcher was interested in seeing if the influence of the structural facets was solely influential by itself or as a combined influence on the readers' text comprehension (RQ3). For the mean scores of the recognition memory questions and the problem-solving recall memory questions, there was no significant interaction between the structural facets. Of course, these results did not necessarily surprise the researcher, since no previous research definitely said there should be a combined influence. Most previous research in the areas of education, psychology, and newspapers, pointed at certain individual structural facets influencing text comprehension 
(Reed, 2006; McNamara et al., 1996; Newton, 1994; Salmerón et al., 2006; Singer \& Kintsch, 2001; Kendeou \& van den Broek, 2007; Lin et al., 2002; Adaval al et., 2007; Caillies et al., 2002; David \& Kang, 1997; Friel et al., 2001). Yet, the mean scores (Table 17) did suggest possibly when not considering a reader's PK level that for both recognition memory questions and problem-solving recall memory questions HTC science articles get better mean scores when CGE are present and LTC science articles get better means scores when CGE are absent. These results suggested what prior research has already said that the more complex the text, the more visuals are needed. Of course, these results do not consider the readers' PK levels.

Upon taking the PK levels of the readers into the equation, there was still no significant interaction seen. The mean scores (Table 18) found, however, did show results heading in the direction of hypothesis 2 . The difference between the mean scores was smaller for readers with high PK level than readers with low PK level when looking between whether or not a CGE was present. This result suggests that the presence of CGE did not significantly influence text comprehension of readers with high PK level as much as it did for readers with low PK level. In addition, readers with low PK level usually scored better on HTC when CGE were present for both recognition memory questions and problem-solving recall memory questions as well as on LTC for recognition memory questions (RQ1). High PK readers found that CGE were helpful for problem-solving recall memory questions despite the text complexity and for recognition memory questions when the science article was HTC (Table 18). However, actual text comprehension was not the only side of text comprehension to find influence by the structural facets. 
Second, since the prior sections focused on the results from the actual text comprehension (memory) mean scores, this perspective allows for examination of the third part of Walter Kintsch's definition of text comprehension: perception. When examining the perception questions, previous research suggested that their perception should find more influence from their PK levels than how much they actually understood and were able to take in from the article (H3). Thus, a high PK reader should give a higher rating compared to a low PK reader. When perception underwent a bivariate correlation analyses, it was found to correlate with both PK and actual text comprehension for the question about interest in the article's topic (Question 12). However, the Pearson Correlation Coefficients between perception of an online science article and actual text comprehension proved to be larger for problem-solving recall memory (Table 20). When the researcher put these Pearson Correlation Coefficients into a coefficient comparison equation for the situation when the coefficients come from the same sample, only problem-solving had a significant $(\mathrm{p}=0.05)$ difference $($ Cohen $\&$ Cohen, 1983). Unfortunately, this result gives the reverse of the expected result (H3).

Perception also had a significant interaction between text complexity and CGE (RQ3). The perception question, which concerned the article's ability to explain the topic (Question 11), showed that the presence of CGE influenced mean scores on both levels of text complexity (Table 19 and Figure 7). When the article was HTC, the presence of visual decreased the mean scores, while the presence for LTC articles increased the mean scores. This suggests that the participants had a better perception of the article's ability to explain when either the article was LTC and there were CGE or article was HTC and 
there were no CGE. Of course, there was no significant interaction with readers' PK levels, so whether this holds true for all readers is not clear.

In conclusion, the structural facets of an article do influence readers' text comprehension (RQ1). Therefore, it is important for science journalists and the science media to consider these structural facets when putting together a science article. By itself, text complexity had a significant effect on low PK readers when the text complexity was high. This effect was visible in the results looking at the interaction between text complexity and the presence of CGE (Table 17). Readers with high PK level had higher mean scores with HTC articles, while readers with low PK level have higher mean scores with LTC articles (Table 18). At the same time, the perception of understanding the explanation of the topic of an article finds a combined influence from both structural facets. Thus, the usage of terminology and explanation needs consideration. Preferably, the writer should use less technical terminology, or at least, define relevant terms and phrases more clearly but not necessarily as detailed. When this task becomes too difficult, the presence of the CGE might help a HTC science article. For the presence of CGE helps low PK readers when reading a HTC science article, especially when they lack the PK needed for problem-solving, but these same readers require no CGE for LTC science articles for problem-solving questions. Thus, if a science journalist needs to make the text more complex or is unable to balance terminology and explaining it, he or she must make sure to have a visual of some type. It will aid in making sure the points of the article comes across clearly and without bogging down the text. 


\subsection{LIMITATIONS OF THE RESEARCH \& FUTURE RESEARCH}

This study's exploration of a reader's text comprehension of a science article has answered a few research questions and proven true or false a few hypotheses, but at the same time, it has brought to light new ones. They exist due to the constraints of the experiment and perhaps due to unforeseen issues that arose either during the experiment or during analysis. These limitations have brought about new possible ways and places for future studies to explore.

The first limitation came about due to the type of participants involved. Most of them tended to be journalism students, since the researcher was only able to recruit college students from journalism courses (Table 8). There were 11 non-journalism students whose results were used in the final analysis, but that was due to them being in introductory journalism courses. Therefore, the results from this study can only be generalized in terms of the University of Missouri's Journalism School, but not any wider yet. It might also explain the small range of PK levels, and the small range of scores of actual text comprehension (memory) and perceived text comprehension. It might also explain why the education background (Table 7) and the exposure to science magazine background (Table 9) did not seem to coincide significantly with readers' PK levels.

Thus, there would first need to be a broader study done on students from a variety of academic backgrounds, particularly from the science and engineering departments as well as the arts and English departments. These types of students would present a wider range of academic backgrounds, experience, and interests. As previously mentioned, these factors tend to influence readers' PK levels and perception significantly. Therefore, any future research would need to pull students from such areas as listed above to get a more 
accurate scale of PK levels. Second, the research suggests an analysis must be made of the audiences of different science media and science communicators. They often tend to write for a particular prior knowledge level in mind. Obviously, it would be preferred that the variation could be eliminated, but before that understanding the people who are reading The New York Time's science section and the local metro science section could give later researchers an idea what to expect when the experiment is run with people outside of a university. This task would present a good opportunity for a pre-testing through surveying and interviewing science writers and communicators, and through focus groups of the science media's audience.

A second limitation might be due to the article topics chosen. The researcher chose a range of topics to allow for a broader application to the coverage of science and technology. They were reflective of topics that are or have been important to the U.S. public. These include astronomy and planets (Article 1), genetically engineered crops (Article 2), bird flu and health (Article 3), and water quality (Article 4). However, after running participants and debriefing them afterwards, a few participants mentioned that they were more familiar with the topics on Pluto losing its planetary status (Article 1) and the spread and origin of bird flu (Article 3) (Mann, 1999; Sato, 2007; McCarty, 1997; Mackenzie, 2006). This familiarity might have shifted the text comprehension scores higher in these articles, since participants might have known more prior to reading the article and been more interested in them. Future research might want to look into this impact or find a way to eliminate it. One way might be to do a pre-test to see how familiar a sample population is to the article topics. Then steps could be taken to either 
remove the articles whose topics are too familiar or find a way to take the familiarity into account.

A third limitation might have to do with the reading strategy of the participants. The researcher had controlled the format of the article. At the top was the title followed by the writer's name. Then underneath was the text with the visuals appearing beside every third paragraph. However, it is quite possible that some participants might not have read as they went down the page, referring to the CGE when one popped up. Instead, if a participant noticed the CGE prior to reading or skimmed the reading first, he or she might have made a quick reference to them before hand. This reading strategy is common for newspapers readers (David \& Kang, 1998). This fact leads the researcher to wonder if similar variations in reading exist for an online science article. Future research might want to explore this mental strategy of cognitively processing information to see if it does influence a reader's text comprehension of a science article, and to what extend this influence exists in an online format.

Other limitations were due to the structural facets used as the study's stimuli. Both facets were controlled or manipulated to eliminate issues. This tactic limited the study, but at the same time, some issues might have arisen leading to further limitations and need for further research. Text complexity results showed some significance, confirming previous research. However, the scores lack of significance for problem-solving recall memory might be due to not enough difference between the two levels of text complexity. While the range of students with different backgrounds (Table 8) might help eliminate a need for too extreme versions of text complexity, it might also be helpful to set the levels of text complexity further apart. In future research, the researcher suggests 
some pre-tests are required, testing different versions of the articles to find the extreme versions for LTC and HTC. Perhaps an examination of just text complexity, considering readers' PK levels, is required before taking other structural facets of the article into account, such as CGE.

Since the CGE found no significant effect from the readers' PK level, this structural facet in particularly needs a closer examination. There could be many reasons behind CGE not finding significance. One could be that this type of visual just does not appeal to a reader of science and technology. Not every participant mentioned a difficulty with the use of the CGE, but some obviously did have issues with it. Therefore, it might be interesting to explore whether the readers simply choose not to use the CGE or if they were unable to use them. If the first is true, then it might be said that relevance or importance of the CGE does matter. Perhaps low PK levels do not feel as drawn to the use of these visuals, at least in terms of science articles. There could also be an impact from the quality or composition of the CGE. Psychologically, different readers react differently to the colors used in a visual, the structure of the visual, the presentation of the visual, and the balance of text and imaginary used by the visual. So perhaps CGE utilized for the articles repelled the readers, which discouraged them to be used. The researcher suggests a further study specifically on visuals to see which type of visuals peek interest of different PK level readers of science articles.

If it was an inability to use them, then perhaps an examination of their presentation is required. For this study, they were placed in shrunken form beside the text and could be clicked for pop-up window of the full-sized version of the CGE. However, during debriefing, a few of the participants pointed out an inability to use them, because they did 
not realize they could click the smaller image or after clicking them, they ran into issues using the pop-up window. The researcher did not foresee these issues, but she must admit, despite holding the presentation of them constant, it could have an effect on the influence of CGE. A suggestion would be to do a more detailed content analysis on science Websites and science magazine Websites to figure out what types of layouts are utilized when visuals are present. Another experiment could go a step further and compare these different types of visuals in an online format.

Of course, the answer could simply be the type of visual utilized. One suggestion is to do a content analysis of science articles to see actually what type of visuals are used by the science media with a possible comparison done between media formats or different types of media within the same format, such as a mainstream science magazine versus a trade science magazine and online science articles versus print science articles. This will give a good cross section of what is in use in terms of the different PK levels. Then perhaps using this data, a researcher can choose the best visuals used for a comparison experiment of either just low PK level or a mixed group of PK levels. This would also work for looking between the influence of static visuals and dynamic visuals. Both present different types of information and used in only an online format.

\subsection{WHAT IT MEANS TO CURRENT RESEARCH}

This study is among the first research into text comprehension in the area of the science media. Essentially, the researcher has taken theories, models, and ideas that have been examined either in areas related to science learning, such as education and 
psychology, or in other areas of the media, such as newspapers, and applied them to this specific area of the media and communications. In an area like science reporting, understanding how people cognitively process information from text is vital to writing it clearly and accurately. It relies heavily on the schemata of the readers, who must have some previous knowledge to read the articles that often do not have everything spelled out or explained neatly. That was why the researcher first posed this study and dared to experiment on two structural facets.

The study has shown that text complexity does play a strong role in readers' text comprehension, but CGE do not seem to have as significant impact on text comprehension by itself. There does seem to be somewhat of a combined influence from the two structural facets, but so far, only in terms of how well the article explained the topic. At the same time, individual's PK level will cause a variation in how much actual text comprehension (memory) and perceived text comprehension is going on. Therefore, this study has become the first step into applying these theories and ideas, laying out a foundation of where future research can progress.

This study and those to follow present a clearer picture of how the science media and others communicating science information to the general population of the world can reach them. If those communicating science and technology information are going to thrive and help inform the general population around the world about what is happening in areas of science and technology, they must strive to be as clear and detailed as possible. Their presentation and explanations must get the point and facts across to the readers. For transparence and clarity are vital to connecting with one's readers. 


\section{BIBLIOGRAPHY}

Adaval, R., Isbell, L.M., and Wyer Jr., R.S. (2007). The impact of pictures on narrativeand list-based impression formation: A process interference model. Journal of Experimental Social Psychology. 43. 352-364.

Brooks, P.H., Arnold, D.J., and Iacobbo, M. (1977). Some Cognitive Aspects of Reading Comprehension. Peabody Journal of Education. 54(3). 146-153.

Caillies, S., Denhière, G., and Kintsch, W. (2002). The effect of prior knowledge on understanding from text: Evidence from primed recognition. European Journal of Cognitive Psychology. 14(2) 267-286.

Cohen, J. \& Cohen, P. (1983) Applied Multiple Regression/Correlation Analysis for the Behavioral Sciences. Hillsdale, N.J. : Lawrence Erlbaum Associates. (Second Edition)

Curcio, F.R. (1987). Comprehension of Mathematical Relationships Expressed in Graphs. Journal of Research Mathematics Education. 18(5). 382-393.

David, P. and Kang, J. (1998). Pictures, high-imaginary news language and news recall. Newspaper Research Journal. 19(3). 21-30.

Evans, G. and Durant, J. (1995). The relationship between knowledge and attitudes in the public understanding of science in Britain. Public Understanding of Science. 4. 5774.

Falk, J.H., Storksdieck, M., and Dierking, L.D. (2007). Investigating public science interest and understanding: evidence for the importance of free-choice learning. Public Understanding of Science. 16. 455-469.

Field, H. and Powell, P. (2001). Public understanding of science versus public understanding of research. Public Understanding of Science. 10. 421-426.

Friel, S.N., Curcio, F.R., and Bright, G.W. (2001). Making Sense of Graphs: Critical Factors Influencing Comprehension and Instructional Implications. Journal for Research in Mathematics Education. 32(2). 124-158.

Gunter, B. (2000). Media Research Methods. Thousand Oaks, CA: Sage Publishers Ltd.

Hanley, J.E.B, Herron, C.A., and Cole, S.P. (1995). Using Video as an Advance Organizer to a Written Passage in the FLES Classroom. The Modern Language Journal. 79(1). 57-66. 
Herron, C., Cole, S.P., Corrie, C., and Dubreil, S. (1999). The Effectiveness of a VideoBased Curriculum in Teaching Culture. The Modern Language Journal. 83(4). 518533.

Horrigan, J. (2006, November). The Internet as a Resource for News and Information about Science. Retrieved February 19, 2008. Pew Internet and American Life Project.

Kendeou, P. and van den Broek, P. (2007). The effects of prior knowledge and texture structure on comprehension processes during reading of scientific texts. Memory \& Cognition. 35(7) 1567-1577.

Kintsch, W. (1988). The Role of Knowledge in Discourse Comprehension: A Construction-Integration Model. Psychological Review. 95(2) 163-182.

Kintsch, W. (1998). Comprehension: A Paradigm from Cognition. New York, NY: Cambridge University Press.

Kintsch, W. (2005). An Overview of Top-Down and Bottom-Up Effects in Comprehension: The CI Perspective. Discourse. 39(2\&3) 125-128

Kua, E., Reder, M. and Grossel, M.J. (2004). Science in the news: a study of reporting genomics. Public Understanding of Science. 13. 309-322.

Lang, A. (2000). The Limited Capacity Model of Mediated Message Processing. Journal of Communication. 50(1) 46-70.

Lang, A. (2006). Using the Limited Capacity Model of Motivated Mediated Message Processing to Design Effective Cancer Communication Messages. Journal of Communication, 56, S57-S80.

Lin, L-M., Zabrucky, K.M., and Moore, D. (2002). Effects of Text Difficulty and Adults' Age on Relative Calibration of Comprehension. The American Journal of Psychology. 115(2). 187-198.

Linderholm, T., Everson, M.G., van den Broek, P., Mischinski, M., Crittenden, A., \& Samuels, J. (2000). Effects of Casual Text Revisions on More- or Less-Skilled Readers' Comprehension of Easy and Difficult Texts. Cognition and Instruction. 18(4). 525-556.

Long, M. (1995). Scientific explanation in US newspaper science stories. Public Understanding of Science. 4. 119-130.

Macedo-Rouet, M., Rouet, J-F., Epstein, I., and Fayard, P. (2003). Effects of Online Reading on Popular Science Comprehension. Science Communication. 25(2). 99-128. 
Mackenzie, D. (September 2006). Instant Expert: Bird Flu. New Scientist. Accessed: September 15, 2008. http://www.newscientist.com/channel/health/bird-flu

Mann, C.C. (1999). Future Food: Bioengineering: Genetic Engineers Aim to Soup Up Crop Photosynthesis. Science. 283(5400). 314-316.

McCarty, P.L. (1997). Microbiology: Breathing with Chlorinated Solvents. Science. 276(5318).1521-1522.

McKeown, M.G., Beck, I.L, Sinatra, G.M, \& Loxterman, J.A. (1992). The contribution of prior knowledge and coherent text to comprehension. Reader Research Quarterly. 27(1). 79-93.

McNamara, D.S., Kintsch, E., Songer, N.B., and Kintsch, W. (1996). Are Good Texts Always Better? Interactions of Text Coherence, Background Knowledge, and Level of Understanding in Learning From Text. Cognition and Instruction. 14(1) 1-43.

Miller, J. D. (1998). The measurement of civic scientific literacy. Public Understanding of Science. 7. 203-223.

Miller, J.D. (2004). Public Understanding of, and Attitudes toward, Scientific Research: What We Know and What We Need to Know. Public Understanding of Science. 13. 273-294.

National Institute of Allergy and Infectious Diseases. (March 6, 2008). NIAID's Role in Addressing Antimicrobial Resistance, NIH. Retrieved March 29, 2008. From the National Institutes of Health Web site:

http://www3.niaid.nih.gov/topics/antimicrobialResistance/NIAIDResearch/niaidsRole .htm

Newton, D.P. (1994). Supporting the Comprehension of Tabulated Data. British Educational Research Journal. 20(4). 455-463.

Norris, S.P., Phillips, L.M. and Korpan, C.A. (2003). University Students' Interpretation of Media Reports of Science and its Relationship to Background Knowledge, Interest, and Reading Difficulty. Public Understand of Science. 12. 123-145.

Organisation for Economic Co-operation and Development. (2003). The PISA 2003 Assessment Framework - Mathematics, Reading, Science and Problem Solving Knowledge and Skills. International: Author.

Pardo, R. and Calvo, F. (2004). The Cognitive Dimension of Public Perceptions of Science: Methodological Issues. Public Understanding of Science. 13. 203-227.

Reed, S. K. (2006). Cognitive Architectures of Multimedia Learning. Educational Psychologist. 41(2). 87-98. 
Salmerón, L., Kintsch, W. and Cañas, J.J. (2006). Reading strategies and prior knowledge in learning from hypertext. Memory \& Cognition. 34(5) 1157-1171.

Sanjosé, V., Vidal-Abarca, E., and Padilla, O.M. (2006). A Connectionist Extension to Kintsch's Construction-Integration Model. Discourse Processes. 42(1) 1-35.

Singer, M. and Kintsch, W. (2001). Text Retrieval: A Theoretical Exploration. Discourse Processes. 31(1). 27-59.

Shapiro, M. (1994). Signal Detection Measures of Recognition Memory. In Annie Lang. Measuring Psychological Responses to Media Messages. Hillsdale, NJ: LEA. pp 133148.

Soter, S. (January 2007). What is a Planet? Scientific American. 296(1). 34-41.

Tobias, S. (1994). Interest, Prior Knowledge, and Learning. Review of Educational Research. 64(1). 37-54.

Yarros, R.A. (2006). Is It the Medium or the Message? Structuring Complex News to Enhance Engagement and Situational Understanding by Nonexperts. Communication Research. 33. 285-309

End Notes:

${ }^{\mathrm{i}}$ The term of prior knowledge is abbreviated to PK for this research paper.

${ }^{\text {ii }}$ Complex graphical elements are an author created term for all elements used in the articles other than the text, title, and byline.

iii The term for the two versions of text complexity is abbreviated to HTC for high text complexity and LTC for low text complexity for this research paper.

${ }^{\text {iv }}$ Problem-solving recall memory is a measuring variable standing in for part of text comprehension and is a researcher created variable. It is a combination of recall memory and problem solving.

${ }^{\mathrm{v}}$ The term of the public perception of science is abbreviated to PPS for this research paper. 